Iberian Journal of the History of Economic Thought

ISSN-e: 2386-5768

http://dx.doi.org/10.5209/ijhe.69404

\title{
John Maynard Keynes, cuantitativista renegado ${ }^{1}$
}

Fernando Méndez Ibisate ${ }^{2}$

Recibido: 30/09/2019 / Aceptado: 12/02/2020

Resumen. El giro radical dado por John Maynard Keynes en su Teoría General de 1936 tuvo raíces en su teoría y política monetarias que, más que un proceso evolutivo, resultó un abandono completo de la teoría cuantitativa monetaria, sobre la que había asentado sus obras previas, y la renuncia al objetivo de estabilidad de precios y la política monetaria como instrumento para encauzar las perturbaciones de la actividad y desempleo de recursos. En la Teoría General, Keynes centra el problema en el sistema económico de mercado, que produce tales resultados desastrosos de forma inherente y persistente.

El trabajo explica este cambio teórico radical, analizando su contenido o fondo y sus posibles razones, cuya catálisis establezco en los acontecimientos de 1925 .

Términos clave: John Maynard Keynes; teoría monetaria; política monetaria; cuantitativismo o monetarismo.

Clasificación JEL: B22, B31, E12

\section{[en] John Maynard Keynes, a Renegade Quantitativist}

Abstract. The radical turn taken by John Maynard Keynes in his 1936's General Theory had roots in his monetary theory and policy that, rather than in an evolutionary process, resulted in a complete abandonment of the monetary quantitative theory, on which he had based his previous works, and the renouncement to the objective of price stability and to the monetary policy as an instrument to solve the disturbances of activity and unemployment of resources. In the General Theory, Keynes focuses the problem on the market economic system, which produces such disastrous results in an inherent and persistent way.

The paper explains this radical theoretical change, analyzing its content or background and its possible reasons, whose catalysis I establish in the events of 1925.

Keywords: John Maynard Keynes; monetary theory; monetary policy; quantitativism or monetarism.

JEL classification: B22, B31, E12

Sumario: 1. Introducción. 2. Breve consideración sobre la teoría monetaria cuantitativa. 3. Keynes cuantitativista. 3.1. Indian currency and finance (1913). 3.2. The economic consequences of the peace (1919). 3.4. "The economic consequences of Mr. Churchill" (1925). 3.5. A treatise on money (1930 y 1931). 4. Keynes renegado: la teoría cuantitativa, ¿caso particular o un imposible? 5. Conjeturas sobre un cambio drástico: a modo de conclusión. Bibliografía.

Cómo citar: Méndez Ibisate, F. (2020): “John Maynard Keynes, cuantitativista renegado" en Iberian Journal of the History of Economic Thought 7(1), 45-64.

\section{Introducción}

En su obra Teoría general de la ocupación, el interés y el dinero (1936), Keynes rechaza la denominada "teoría cuantitativa del dinero" y la ley de Say para construir un nuevo modelo de funcionamiento del sistema económico, basado en nuevos principios teóri$\cos$, entre los que la demanda efectiva es fundamento básico ${ }^{3}$. Centrado en sus ideas monetarias, teóricas y aplicadas, este trabajo analiza ese cambio radical adoptado por John Maynard Keynes, expone su contenido y fondo, y explica sus posibles razones.

Tanto por la diversidad de tareas, ocupaciones, problemas o actividades a los que dedicó su gran talento y en los que desarrolló su profesión y vida, como porque en cualquiera de ellos mostraba opiniones diversas y posturas diferentes, incluso contradictorias, procurando siempre originalidad, sorpresa, admiración y, en última instancia, fascinación de sus interlocutores, resulta natural, y hasta consustancial

\footnotetext{
Agradezco los comentarios de los revisores anónimos que, lógicamente, quedan eximidos de cualquier responsabilidad.

Universidad Complutense de Madrid

Facultad de Ciencias Económicas y Empresariales

3 He tratado este asunto en Méndez Ibisate (2006; 2012 y 2014b). Como he reiterado anteriormente, con evidente fracaso, el término "teoría cuantitativa del dinero" es una mala denominación, pues dicha teoría no explica, ni pretende explicar, el dinero o su cantidad (oferta) en la economía, sino que trata de explicar el nivel general de precios, o su evolución dinámica, y lo hace mediante la cantidad de dinero con relación a sus necesidades o demanda; es decir, a través de las disponibilidades líquidas del sistema económico. Por ello, con el profesor Schwartz, considero más adecuada y descriptiva la denominación "teoría de la 'cantidad de dinero' de los precios", entendiendo que se trata del nivel general de precios y no de los precios relativos.
} 
con Maynard Keynes, ese cambio de ideas o análisis teórico así como que su obra haya sido objeto de interpretaciones múltiples, e incluso tergiversaciones interesadas.

Pero, aunque gestada de forma progresiva, su transformación teórica, analítica y práctica fue radical. Particularidad que ha tendido a explicarse, bien centrándose en la Teoría General (1936) como estructura única y central del análisis y pensamiento de Keynes, bien, cuando se consideran otras obras económicas, explicando las discrepancias analíticas, teóricas y de política económica como resultado de una evolución propia de los acontecimientos históricos que le tocaron vivir, principalmente la Gran Depresión de los años treinta del siglo pasado.

El asunto es complejo ya que, aunque incompletas, ninguna de esas interpretaciones o percepciones es irrelevante o tergiversa la realidad, pues su libro principal de 1936 ha eclipsado el resto de sus contribuciones y, atendiendo a su propia obra y evolución, Keynes quedó profundamente afectado por los acontecimientos y cambios convulsos del período que le tocó vivir, en los que participó activamente tratando de enderezarlos, aunque finalmente tuvo que aceptar el derrumbamiento del mundo victoriano, al que pertenecía y se sentía ligado a pesar de haber combatido sus valores y moral, incluidas la pérdida de posición internacional política, social, económica, diplomática y hasta moral que había ocupado Gran Bretaña; y, lo que para él era peor, la irrupción de los Estados Unidos, al fin y al cabo unos toscos y renegados descendientes británicos, como nación o sociedad líder y referente. Ante él se derrumbaba $s u$ civilización en manos de unos tenderos puritanos y vulgares.

Además, existen elementos de continuidad en la evolución de su trabajo y su pensamiento económico que permiten atribuir las posibles diferencias a un proceso de radicalización en sus postulados o principios, resultado de su experiencia, lo que justificaría considerar su cambio como progresivo y no radical. Pero la realidad es que tal continuidad y evolución se produce, precisamente, hasta los primeros años treinta y en el marco de una afinidad de pensamiento y esquema teórico común, que manifiesta aún más el cambio en su obra de 1936: de defender la teoría cuantitativa a oponerse o rechazarla y considerar la política monetaria inoperante para salir de una crisis o depresión, esencialmente no por la presencia de una "trampa de liquidez" sino porque, dadas las cualidades intrínsecas que Keynes le presupone, el dinero no produce los resultados que suelen adjudicársele ${ }^{4}$.
Keynes no siempre tuvo estas ideas y desde sus inicios como economista, en 1906, hasta 1931, siguió un esquema teórico monetario cuantitativo centrado en la estabilidad de precios, postulando, y tratando de influir para que se determinasen y ejecutasen, políticas monetarias activas para luchar contra las fluctuaciones económicas o los procesos de auge y depresión. Y, aunque su propósito, análisis teórico o enfoque desplegados en la Teoría general de 1936 sean bien distintos, cabe considerar que el planteamiento de que la política monetaria puede no ser efectiva para luchar contra las fluctuaciones económicas, o la noción de que puede ser contradictorio y resultar en un problema mayor utilizar la liquidez del sistema como remedio para situaciones de auge o depresión, que normalmente han sido creadas por las autoridades mediante previa manipulación de las disponibilidades líquidas o de variables que las afecten, son compartidos por economistas tanto de la escuela austríaca como monetaristas o cuantitativistas.

Pero Keynes pasó de seguir los fundamentos teóricos y de política monetaria intelectualmente heredados de Cambridge y su maestro Alfred Marshall, a abandonar toda esperanza en el funcionamiento y los elementos correctores del propio sistema de mercado. Curiosamente, aunque en la Teoría general (en adelante también TG) admitió y propuso como correctivo de tales "fallos" la intervención del Estado en la economía, particularmente en los mercados de inversión, ahorro y consumo, sin embargo consideró ineficaz o inútil la intervención de la autoridad en los mercados monetario y financiero 5 . Keynes fue siempre, sin duda, un convencido y diestro intervencionista que defendió la perspectiva de una necesaria reparación, ajuste, conducción o manipulación del sistema económico, aunque en distintos grados y con diferentes postulados analíticos o modelos teóricos a lo largo de su carrera intelectual.

A fin de mostrar tanto su unicidad teórica hasta la TG, como su evolución y posterior mudanza en 1936, este trabajo recoge una exposición simple de las principales obras de J. M. Keynes en materia monetaria y plantea una explicación de su cambio. Cambio que, ciertamente, no se debe a una transformación de doctrinario del mercado a defensor a ultranza del intervencionismo y el Estado: ni postuló jamás, como sabemos, la socialización de la economía al estilo de la Unión Soviética, sino que se trataba más bien de un intervencionismo social —en su caso, elitista - inspirado en los postulados de Cambridge y Marshall, heredero del ambiente que venía desarrollándose y evolucionando desde la segunda mitad del

\footnotetext{
Véase Méndez Ibisate 2006, 27 y ss. Véase también Méndez Ibisate 2012, 52-83. Todavía hoy, durante la Gran Recesión de 2007 a 2014 y años después, sigue repitiéndose la idea de que las inyecciones de liquidez son una política monetaria keynesiana, del Keynes de 1936. Error que cometen no sólo sus seguidores más firmes sino también sus detractores; por ejemplo, Ebeling 2004, 15 y 16.

Keynes abandona el descrédito o ineficacia de la política monetaria en sus contribuciones al plan de Bretton Woods, en 1944, donde muestra un retorno al monetarismo intervencionista. Quienes realmente debían intervenir en la economía era una élite de burócratas o funcionarios especializados que guiarían a los políticos; éstos disponían del poder ejecutivo o administrativo sobre las medidas propuestas, pero raramente del talento preciso. Entrecomillo la palabra "fallos" aplicada a los mercados pues, tras las aportaciones de Ronald Coase (1960) sabemos que es inexacto atribuir, sin más, fallos a los mercados.
} 
siglo $\mathrm{XIX}^{6}$; ni su adhesión a la teoría cuantitativa le impedía, como tampoco a otros, abrazar y postular un intervencionismo de las autoridades, que, eso sí, fue creciente o más intenso a medida que se desarrollaban los acontecimientos y las crisis; ni la teoría cuantitativa, como marco teórico-analítico era, ni es, contraria o impide per se el intervencionismo de la economía, incluso en los grados planteados por la TG o, aún más, en los actuales niveles de las economías occidentales, lo que habría sido compatible con su peculiar percepción del sistema económico. Sin embargo, Keynes rompe con la teoría cuantitativa y la ley de los mercados de Say porque se convence de que las leyes del mercado - de las que ambas son parte fundamental - no funcionan, no operan, y deben determinarse de manera forzada en base a los fundamentos analíticos nuevos que establece en la TG - de los que el principio de la demanda efectiva es el núcleo-, ya que su razonamiento le obliga a justificar por qué no funcionan las leyes, estructuras y procesos de los mercados y a explicar cómo lo hacen. Sobre la base de ese nuevo armazón teórico-analítico, únicamente se pueden lograr los resultados positivos del sistema de mercado - que no pretende desechar - mediante la intervención de la economía en "esa", no otra, dirección (el poder no tiene ojos ni objetivos propios, sino el bien común) de replicar el mercado; intervención que es o debe ser plena en parcelas como la inversión o aquellas que afecten a la demanda efectiva.

En las siguientes páginas presento unas consideraciones relevantes de la teoría "cantidad de dinero" de los precios para ubicar las ideas de Keynes, hasta su Treatise on Money (1930) inclusive, dentro de la corriente o grupo de pensadores monetaristas que han propugnado la intervención discrecional de las autoridades como método de afrontar y corregir las fluctuaciones económicas y los problemas derivados de ellas, frente a aquellos autores monetaristas que han sostenido que, salvo adecuaciones a los cambios en su demanda o condiciones de su necesidad, no debe alterarse la liquidez del sistema (oferta monetaria), circunscribiendo la actuación de las autoridades monetarias a reglas fijas o, todo lo más, manejos cuasiautomáticos de las disponibilidades líquidas del sistema.

Tras ello expongo el análisis que Keynes realiza del dinero y la política monetaria en la TG, proponiendo que su cambio es más radical que evolutivo: un cuantitativista que reniega de sus principios y fundamentos analíticos y, sobre la base del principio de la demanda efectiva, pasa a considerar que los mecanismos de mercado no operan por sí mismos en absoluto o que, dejados a su propia acción, conducen a la subactividad y desempleo de recursos, incluso en equilibrio.

Finalmente, planteo qué elementos y hechos pueden explicar tal cambio drástico de modelo analítico y rechazo de la teoría cuantitativa cuyo armazón teórico ha retornado y vuelto a integrarse, con variaciones, detalles o desarrollos, en los modelos macroeconómicos al uso, incluso neokeynesianos o Newkeynesians, y que el propio Keynes retoma en Bretton Woods.

\section{Breve consideración sobre la teoría monetaria cuantitativa $^{7}$}

La teoría de la "cantidad de dinero" de los precios, teoría cuantitativa o monetarismo sostiene básicamente, como afirmó Milton Friedman, que "la inflación es siempre y en todas partes un fenómeno monetario en el sentido de que solo es y puede ser producida por un incremento más rápido de la cantidad de dinero que de la producción.".

Se trata de una explicación de la variable conocida como "nivel general de precios" o, de forma más desarrollada y precisa, de su evolución dinámica (a lo largo del tiempo), a partir de la cantidad de dinero u oferta monetaria - de su variación también - que en sentido amplio puede entenderse como las disponibilidades líquidas del sistema económico o liquidez.

La teoría establece, pues, una relación causal o funcional que discurre desde la variable cuantitativa monetaria hacia el nivel general de precios, o sus respectivas tasas de variación, frente a lo que muchos pensadores económicos han sostenido y determinado, empezando por diversos mercantilistas de todos los tiempos, de que las variaciones en la cantidad de dinero o disponibilidades líquidas no afectan a los precios (al nivel general), sino a la actividad - producción, crecimiento, industria, comercio, actividad mercantil, inversiones, etc.- y el empleo' ${ }^{9}$. Tal interpretación es incorrecta tanto porque sólo atiende a una parte del fenómeno o de los movimientos que tienen lugar como consecuencia de alteraciones bruscas y bajo ciertas condiciones de las disponibilidades líquidas, incurriendo normalmente en el error de confundir precios relativos con precios absolutos o nivel general de precios, como porque tampoco para la teoría cuantitativa el dinero es neutral ${ }^{10}$. Es decir, la teoría cuantitativa

\footnotetext{
Véase Méndez Ibisate 2018.

Mantengo la denominación extendida y tradicional de teoría cuantitativa del dinero, aunque sea desconforme con ella. Asimismo, me ciño fundamentalmente al caso de variación dinámica al alza del nivel general de precios, o inflación, aunque la argumentación utilizada pueda también aplicarse, con movimientos contrarios, a una disminución de la oferta monetaria y el nivel general de precios o deflación.

Friedman 1963, 17. Reproducido en Friedman 1968b, 39. Esto no implica que toda alteración en la liquidez u oferta monetaria suponga o signifique necesariamente una inflación o proceso inflacionario.

9 Una variante de tal idea es la que sostiene que la relación es inversa: desde la actividad, la producción o las transacciones hacia la cantidad de dinero o la necesidad de disponibilidades líquidas de la economía.

10 Suele argumentarse que la defensa de la teoría cuantitativa equivale a sostener la neutralidad del dinero en economía. Nada más lejos de la realidad, pues eso es contrario al concepto mismo que del dinero o lo financiero, y su papel en la economía, tenían los autores clásicos y preclásicos. Tal
} 
también considera efectos sobre otras muchas variables, incluidos la actividad y el empleo.

Desde muy temprano, los economistas que explicaron la existencia y funcionamiento de la teoría cuantitativa plantearon que la relación entre disponibilidades líquidas del sistema y nivel general de precios no es inmediata, ni siquiera rápida. Es decir, existen retardos en la transmisión de efectos como parte propia de los procesos que tienen lugar y como consecuencia de la propia transmisión de mecanismos que operan en dichos procesos. Asimismo, establecieron que los movimientos o variaciones tampoco son equivalentes, ni exactamente proporcionales: los movimientos son en la misma dirección, pero incrementos determinados en la cantidad de liquidez $\mathrm{u}$ oferta monetaria no producen efectos similares en cuantía, ni iguales en proporción, en los precios ${ }^{11}$.

También notaron y determinaron que las expansiones monetarias afectan en mayor o menor grado a los precios, pudiendo no hacerlo, según que los niveles de transacciones, producción o intercambios, así como las necesidades y demanda de liquidez (demanda de dinero), experimenten, o no, cambios sustanciales. Así, un aumento o expansión en la cuantía o nivel de las transacciones puede exigir más liquidez o masa monetaria para llevarlas a cabo. Por tanto, si la economía crece, lo que también incluye aumentos de la productividad, mayores disponibilidades líquidas no suponen necesariamente futuros aumentos del nivel general de precios.

Igualmente consideraron que los precios pueden no quedar afectados ante una expansión monetaria si los usuarios cambian pautas de uso, consumo y manejo del dinero. Esto es, la demanda de dinero o de liquidez tenía mucho que decir en el proceso de afección sobre el nivel general de precios, pudiendo también contrarrestar o reforzar, según fuesen sus movimientos, las repercusiones de una inyección de liquidez sobre aquél. De aquí surgió toda una disputa, entre los cincuenta y los ochenta del siglo XX, sobre la estabilidad de la demanda de dinero, entre los seguidores de la teoría cuantitativa y los del Keynes de la Teoría general (keynesianos y neokeynesianos), atribuyéndose a éstos la defensa de una demanda monetaria muy inestable o, al menos, mucho más de lo que pretendían los primeros; ello a pesar de que, como he determinado (Méndez Ibisate 2012, 75-77), Keynes defiende en la TG una estabilidad bastante robusta de la demanda de dinero ${ }^{12}$.

Así pues, contrariamente a lo defendido por autores que, o bien tuercen la teoría del ciclo real de las fluctuaciones o bien sustentan su análisis sobre erróneos fundamentos keynesianos, para la teoría cuantitativa las inyecciones de dinero siempre tienen consecuencias y provocan perturbaciones importantes en las estructuras de preferencias, conjuntos de información (precios relativos), formación de expectativas, cálculos de riesgo e incertidumbre, valoración del tiempo y toma de decisiones en los individuos, aunque sea de forma transitoria hasta que finalmente repercuten en el nivel general de precios, pero siempre después de un lapso de tiempo y nunca de manera proporcional. Es lo que conocemos por el "efecto Cantillon"13.

Finalmente, deben establecerse algunas observaciones de la propia teoría que complican buena parte de las conductas, movimientos o desarrollos que se producen tras una alteración sustancial de las disponibilidades líquidas, fortaleciéndolos o atenuándolos.

Primero, debe considerarse la instalación de expectativas inflacionistas en el transcurso de los efectos y mecanismos que tienen lugar, tanto por vía directa como indirecta. La instalación de expectativas inflacionistas puede, en principio, reforzar la transmisión de efectos expansivos por todos los mercados, incluidos los monetarios y financieros, así como los efectos en el consumo, ahorro, inversión, actividad y empleo, normalmente en la creencia de que lo que sube continuará subiendo; pero también será lo que, en última instancia y de forma definitiva, tuerza la

proposición ha sido defendida tanto por keynesianos como por los economistas austríacos, que han encontrado una divergencia en tal asunto con los monetaristas o cuantitativistas. Por ejemplo, Hayek argumenta que, aunque uno de los impulsos básicos en las fluctuaciones son los desequilibrios o perturbaciones en el lado financiero o monetario, sobre todo manejos de las autoridades en tipos de interés, sin embargo, estima que ese tipo de desequilibrios puede combinarse con otros producidos por cambios técnicos, alteraciones en las preferencias de los individuos o en sus cálculos —normalmente alteraciones inducidas en las tasas de rentabilidad-. Así, Hayek, que conocía bien las obras de Cantillon y Thornton, sostenía que podía ocurrir que los cambios de las disponibilidades líquidas en la economía, muchas veces inducidas por manejos de las autoridades sobre el tipo de interés monetario, no siempre terminasen ejerciendo influencia en el nivel general de precios, aunque sí lo harían sobre los precios relativos con consecuencias reales. Véase Gómez Betancourt (2008). No obstante, Gómez Betancourt afirma que, aunque Hayek demuestre la no neutralidad del dinero, "su propósito era probar su neutralidad" (Gómez Betancourt 2008, 47; 63-64 y ns. 18 y 19; y 66-67.).

11 Esto se debe tanto a la existencia de retardos como a los procesos y mecanismos que tienen lugar en la transmisión de efectos.

12 Como ha señalado Robert J. Barro, aunque la demanda real de dinero era más estable de lo que supusieron los seguidores de Keynes (véase por ejemplo Laidler 1980), lo cierto es que "no es tan estable, muy especialmente en el entorno financiero actual de alta tecnología, pero tampoco lo ha sido a lo largo de la historia" (Barro 2007, 130). Es por esto, por su énfasis en las políticas monetarias activas como forma de suavizar o mitigar los ciclos económicos, junto con el impacto del dinero en la economía real, aunque fuese a corto plazo, que Barro 2007, 129, menciona cierto encaje de las ideas de Milton Friedman con el pensamiento keynesiano, contrario a la teoría cuantitativa. Y a esto apelan los modernos austriacos para señalar errores analíticos o calificar de intervencionista la teoría cuantitativa, aunque otros autores austriacos basan o utilizan, en gran parte, esta teoría, según aquí se plantea, para sus análisis e ideas sobre fluctuaciones económicas. Como precisa Barro 2007, 129-130, Friedman incorpora dos factores que lo alejan de esa lectura o interpretación deformada: la introducción de retardos largos y mutables en las políticas monetarias y, por tanto, en los impulsos monetarios (véase Friedman, 1960), ya considerados e introducidos desde muy temprano en la formulación de la teoría cuantitativa; y la distinción entre normas y autoridades, o "reglas" frente a "discrecionalidad", que luego menciono.

13 Véase Méndez Ibisate (2004b). Considero que Lucas Jr. es impreciso e inexacto cuando sostiene que "Las predicciones centrales de la teoría cuantitativa son que, a largo plazo, el crecimiento del dinero debería ser neutral sobre la tasa de crecimiento de la producción y debería afectar a la tasa de inflación sobre una base de uno a uno." (Lucas 1996, 665). Desde luego, a tenor del "efecto Cantillon", la teoría cuantitativa no establece tal proporcionalidad. 
dinámica de dichos procesos e inicie los ajustes establecidos por la teoría, mediante la elevación de todos los precios, incluido el tipo de interés, una vez los agentes reaccionen ante la incorporación de dichas expectativas.

Estos efectos de la incorporación de expectativas pueden desarrollarse, o también disiparse o desaparecer, lentamente ${ }^{14}$. Y en su aparición y desarrollo tienen importancia las instituciones financieras y bancarias - su papel y actitud dentro de la economía, lo que también depende de la regulación o normativa-, que actúan como catalizadores en los procesos de fluctuaciones económicas, siendo la principal vía de transmisión, tanto de las mayores disponibilidades líquidas como de los mecanismos descritos, la generación y distribución de expectativas o de las demandas especulativas de crédito $^{15}$.

Por otra parte, está el papel de las autoridades en todos los procesos mencionados, empezando por los impulsos o alteraciones iniciales de liquidez, dado que acaparan la producción de dinero, supuestamente en forma de monopolio. Cabe observar que incluso el proceso de instalación de expectativas inflacionistas descrito puede retardarse, difuminarse momentáneamente o confundirse si, como ha experimentado la zona euro durante la crisis de 2008-2014, la autoridad monetaria persiste en forzar los tipos de interés a la baja o mantiene una fuerte expansión de la liquidez que impide artificialmente el ajuste de tipos al alza, evitando que se produzca el incentivo de los deudores a pagar - o de los prestamistas a pedir - intereses más altos y posiblemente reforzando en los agentes económicos expectativas de una recesión futura mayor o más prolongada que dificultará el ajuste de precios al alza de forma rápida y fácil.

La teoría cuantitativa conoce y plantea que las propias intervenciones de política monetaria por parte de las autoridades, mediante el uso de tipos de interés o de expansiones cuantitativas, tienen impactos sobre la demanda de dinero y su estabilidad. El problema en este punto es su cuantificación y correcta atribución de causación ${ }^{16}$.

Además, el banco central puede estimular la actividad y el empleo por más tiempo si, tras una inyec- ción monetaria, convence a los agentes y partícipes del mercado que responderá adecuadamente a cualquier incremento de la inflación, retirando los excesos de liquidez una vez incorporados dichos estímulos. Dicho de otro modo, si el público cree a pies juntillas que lo que en última instancia se provocará es inflación, actuará protegiéndose de sus efectos y consecuencias impidiendo que la actuación de política económica tenga el efecto deseado o previsto. De hecho, el banco central deberá retirar el exceso de dinero, pasado un tiempo, si quiere cumplir su compromiso de prevenir un aumento de la inflación $\mathrm{o}$, de lo contrario, su credibilidad quedará seriamente dañada y, en ocasión venidera, nadie creerá las intenciones de la autoridad monetaria ni se dejará engañar de nuevo, actuando en consecuencia según su conocimiento ${ }^{17}$.

Así pues, los procesos de ajuste descritos por la teoría cuantitativa, tanto a través del mecanismo directo como del indirecto, y los movimientos de las variables o las transmisiones de efectos previstas tendrán lugar, según la teoría, en tanto no se produzcan nuevas o añadidas intervenciones por parte de las autoridades monetarias, o de los gobernantes en otros ámbitos de la economía, que alteen dichos $\operatorname{procesos}^{18}$.

Por ello, la distinción fundamental dentro de los teóricos cuantitativistas es entre aquellos autores que confían en que los mercados funcionan y sus mecanismos de ajuste operan, aunque desde luego no de forma perfecta; y aquellos otros que consideran que los mercados y sus sistemas de ajuste o reglas de estabilidad son o bien demasiado lentos o bien demasiado "imperfectos" y no terminan de retornar a situaciones previas de cierta estabilidad y crecimiento tras sufrir perturbaciones que alteren la economía ${ }^{19}$.

En materia de política monetaria, entre los primeros encontramos a los monetaristas o defensores de la teoría cuantitativa que proponen reglas, más o menos fijas y estables, para la actuación de las autoridades monetarias, pudiendo incluir a R. Cantillon, D. Hume, D. Ricardo o M. Friedman; mientras que los segundos defienden una gran capacidad de actuación y grados de discrecionalidad o arbitrariedad amplios

\footnotetext{
14 Por ejemplo, Friedman señala que Fisher estimaba que se tardaba varias décadas para que se produjese el ajuste completo. (Friedman 1968a, 100). Por ejemplo, Marshall 1965b, 257. Véase Méndez Ibisate 1996, 656, n. 40.

Por ejemplo, Friedman 1968a, 7, n. 2 o Friedman 1969, 101, n. 9. También citado por Laidler 2018, 5.

17 Esta idea, adelantada por Friedman (1968a), junto con Phelps (1967) (véase Méndez Ibisate 2015, 205-207 y 212-221), y enunciada como que sólo los movimientos no anticipados del dinero y el nivel general de precios importan para la actividad económica real, es — en buena parte- un avance de la aplicación de la hipótesis de expectativas racionales a la política monetaria, efectuada por Robert Lucas Jr. a partir de la década de los setenta. Describe, asimismo, los denominados como problemas de inconsistencia temporal. En términos históricos, Alemania o Argentina son dos buenos ejemplos de tales reacciones ante procesos o expectativas inflacionistas, aunque sus episodios respectivos aconteciesen hace muchas décadas; si bien los argentinos han repetido recientemente, en las dos primeras décadas del siglo XXI, situaciones inflacionistas donde han puesto a prueba la incorporación de sus experiencias previas.

18 Por ejemplo, mediante más gasto público que altere la capacidad o composición de demanda o gasto de los agentes privados —incluso afectando a los impuestos presentes o futuros-, o mediante fuertes emisiones de deuda pública que afecten a los mercados financieros y monetarios. Medidas, entre otras, que las autoridades pueden y suelen añadir o combinar con los movimientos en la política monetaria.

19 Salvo en los manuales y como ejercicio teórico para entender el funcionamiento intrínseco de variables y leyes de comportamiento en los modelos económicos generales, nadie considera realmente que haya algo perfecto — equilibrio, competencia, mercado...— en el sistema económico, pues la economía pertenece, está y se desenvuelve en un mundo evidentemente imperfecto. Por ejemplo, es significativa la salvedad que establece Friedman 1968a, 8 [Friedman 1969, 102]: "siempre que se introduzcan [en el sistema de equilibrio de los mercados] las características estructurales reales de los mercados laborales y de productos básicos, incluidas imperfecciones del mercado, variabilidad estocástica en las demandas y ofertas, los costes de recopilar información sobre vacantes de empleo y disponibilidades laborales, los costes de movilidad, etc.".
} 
para dichas autoridades. Entre estos incluiríamos a H. Thornton, J. S. Mill, A. Marshall y J. M. Keynes ${ }^{20}$. En todo caso, ni la teoría, ni —en general- los teóricos cuantitativistas proponen una neutralidad plena del dinero, como suele afirmarse, puesto que ambos grupos o posturas tienen cabida en el supuesto de no neutralidad: puede argumentarse tanto que la política monetaria es inexacta, imprevisible y hasta peligrosa, propugnando, bajo la forma de reglas estables, una mínima discrecionalidad o intervención en materia monetaria y financiera, como también hizo Hayek; pero también sostener que precisamente la influencia y efectos que el dinero tiene, por su no neutralidad, permiten manejos de la autoridad para amortiguar, suavizar o frenar los impulsos, ajustes y movimientos que tienen lugar en los procesos de fluctuaciones económicas, otorgándoles una gran discrecionalidad y capacidad de intervención ${ }^{21}$.

\section{Keynes cuantitativista}

En el marco descrito, Keynes se ubica como discípulo de Alfred Marshall y defensor de una tradición de la teoría cuantitativa que incorpora una importante y creciente intervención de las autoridades, tanto para amortiguar o suavizar los desajustes producidos por las fluctuaciones, originadas muchas veces por factores monetarios o crediticios derivados de decisiones o actuaciones de dichas autoridades, como para corregir las disfunciones o rigideces existentes en los mercados durante los procesos de ajuste, principalmente en el mercado laboral y los salarios, la inversión en existencias o situaciones de ahorro forzoso, ya señaladas por Thornton en $1802^{22}$.

El intervencionismo reformador de Keynes es una constante en sus escritos, si bien es creciente y más resoluto a medida que su obra avanza hacia la TG, donde plantea y sostiene que el sistema económico de libre mercado funciona con desajustes o distorsiones inherentes que lo conducen inexorablemente al desequilibrio, la desocupación de recursos, la deflación y la crisis que sólo pueden resolverse con la intervención de las autoridades, aunque ya no actuando sobre los mercados monetario y financiero. En esta obra, Keynes renuncia a mantener como soporte analítico la teoría cuantitativa del dinero, que sí utiliza y argumenta previamente. Hasta entonces, dicha teoría le permitía la defensa de un intervencionismo y vigilancia sobre la economía por parte de las autoridades para encauzar, corregir y reajustar el sistema económico de forma conveniente. Pero en la TG concibe tal intervención como parte del sustento del propio mercado: un control y actuación permanentes de las autoridades públicas sin los que el sistema económico está abocado a un desequilibrio recurrente o continuo que torna en recesión a largo plazo; al fracaso y la pobreza. Eso sí, nunca propuso la eliminación de la propiedad privada o un sistema comunista, advirtiendo expresamente en la TG que su teoría no aboga "por un sistema de socialismo de Estado que abarque la mayor parte de la vida económica de la comunidad. No es la propiedad de los medios de producción lo que es importante que el Estado asuma"23.

Pero hasta llegar, en un progreso creciente, a los postulados de la TG, incluido su abandono de la política monetaria como instrumento de ajuste o equilibrador para las autoridades, Keynes muestra un análisis teórico y práctico sustentado por la teoría cuantitativa que, en sus primeros escritos y hasta el Tract de 1923 incluido, es claro y brillante.

\subsection{Indian currency and finance (1913)}

Siguiendo las enseñanzas de su maestro Marshall ${ }^{24}$, Keynes enfatiza en este libro la necesidad de que una autoridad central se haga cargo del control y gestión de la moneda para estabilizar los precios. Para tal objetivo, la moneda india debía pasar de un sistema de patrón metálico, que tantos problemas había causado en un país pobre como la India, a un sistema de papel moneda.

En la segunda mitad del siglo XIX y primeros años del XX, la India mantuvo alternancias en su patrón metálico; y aunque fundamentalmente se basó en la plata, la dominación británica obligó en diversas ocasiones a cambiarlo por un patrón basado en el oro, siendo en 1897, por motivos de unificación del sistema monetario en todo el Imperio, que la India adopta el patrón oro. Eso hacía del sistema monetario indio, en la práctica, un sistema de patrón bimetálico, ya que el uso y la costumbre mantenían la circulación de las rupias de plata al tiempo que, en más de una ocasión, padecía de diversos problemas de abastecimiento de metales, especialmente de oro, y de inestabilidades en el valor relativo de ambos metales como

20 Véase Méndez Ibisate 1988, 79-81 y 90-91. Laidler 2018, 8, considera que, lejos de su reciente reputación, Friedman se mostraba en 1967 algo más permisivo o flexible con la intervención de las autoridades, siempre que utilizasen correctamente la política monetaria para impedir que el dinero provocase fluctuaciones de auge y depresión. Aunque es cierto que, rápidamente, se dispone a puntualizar la práctica imposibilidad de tal cosa y las limitaciones de tal discrecionalidad mínima. Friedman 1968a, 14 y 16-17 o Friedman 1969, 107 y 109-110.

21 Desde Adam Smith, y antes, los defensores de la teoría cuantitativa han considerado el dinero no como neutral, sino como algo fundamental para el progreso y crecimiento económicos, sin el que nada habría sido históricamente igual. Véase Humphrey (1991). Sobre Hayek, véase Gómez Betancourt 2008, 65 .

22 Sobre Thornton, véase Méndez Ibisate 2000, 37-42. Para la relación con Marshall, véase Méndez Ibisate 2004a, 382-390. Keynes asistió a las clases sobre dinero y finanzas que Marshall impartía en Cambridge, en 1906, y en sus primeros años como profesor de esa Universidad enseñó teoría pura y aplicada del dinero. Véase Skidelsky 2013, 201.

23 Keynes 1973, 378. Como más adelante señalo, en la gestación y convicción de las disfunciones propias del sistema de mercado influyeron sus creencias derivadas de su formación, a su vez mezcla de estética y diversión intelectual, y su experiencia práctica o real de desmoronamiento del mundo y el sistema económico que hereda, junto con cierta carencia de reacción ágil y precisa del mismo para evitarlo.

24 Véase Méndez Ibisate (1996). También, como complementario, Méndez Ibisate (2018). 
consecuencia de las alteraciones en sus cotizaciones internacionales, pues la extensión de la adopción del patrón oro hizo más escaso este metal, mientras que la plata abundaba tras el descubrimiento de grandes cantidades en Estados Unidos y algunas colonias europeas.

Siguiendo la Ley de Gresham, y debido al mantenimiento del patrón oro en todo el Imperio Británico, la plata en la India desplazaba de la circulación al oro, más valioso, que era acaparado o acumulado para otros usos, incluidos los pagos al exterior. Además, como en las décadas de 1870 y 1880 varios países se habían pasado al patrón oro - entre ellos Alemania, que venía de patrón plata (táler)—, se liberaron importantes cantidades de plata en los mercados, al tiempo que demandaban copiosamente oro, elevando todavía más su valor respecto de la plata; y convirtieron así a determinados países con uso metálico de plata en sus sistemas monetarios, bien por tradición, como fue el caso de la India, bien porque mantenían patrón bimetálico, como en Francia u otros países (Unión Monetaria Latina), en receptores masivos de monedas y lingotes de plata.

Todavía en esta obra, y aunque ya se mostraba muy crítico con el sistema de patrón metálico, Keynes admite y defiende para la India un peculiar patrón de cambios oro, con una circulación controlada oficialmente y basada fundamentalmente en el papel moneda, junto con algunas monedas de plata y otros metales inferiores, que mantuviese artificialmente la paridad con el oro mediante créditos en el extranjero en libras esterlinas. Es decir, propone una transformación del sistema financiero y de pagos indio a uno fiduciario, basado en papel moneda, aunque manteniendo una cierta convertibilidad, que para el público en general lo sería de forma nominal y no efectiva, y que ligara la moneda india - la rupia - a la libra esterlina, a su vez ligada al oro (patrón metálico de cambios). Además, lo que para él era más importante, el sistema monetario y financiero indio quedaría controlado, vigilado e intervenido por una autoridad monetaria, mediante el establecimiento de un banco central, dependiente del Banco de Inglaterra en lo relativo a su relación con el oro, evitando a la autoridad monetaria india tener que estar pendiente del tipo de cambio de la rupia y del mantenimiento de costosas reservas, aunque con sobrada autonomía para ejecutar la política monetaria y así atender a las necesidades de pagos y liquidez del país.

Según Keynes, este sistema de cambios, muy desnaturalizado o meramente nominal, permitía a la India ahorrar mucho en reservas metálicas y confería a su oferta de dinero una mayor elasticidad para poder responder a las necesidades del comercio y las transacciones, siendo especialmente adecuado en un país como la India, donde las necesidades de liquidez para pagos e intercambios era cambiante e imprevisible ${ }^{25}$.
Además, tanto en este libro de 1913, como en el Informe que presentó como miembro de la Comisión Real de la Moneda y Finanzas de la India, Keynes especifica y propone asuntos formales relativos al esquema del sistema financiero propuesto para la India; al proyecto de banco central, con detalles de su funcionamiento y atribuciones; y al manejo de los tipos de descuento para instrumentar la política monetaria. La ausencia de un banco central era, para Keynes, la gran debilidad del sistema monetario indio.

La clave del sistema propuesto por Keynes estaba en la centralización de las reservas, tanto metálicas como de billetes. De un lado, la centralización de las reservas metálicas de oro, dispersas entre el Tesoro y el Banco de Inglaterra, permitiría a Londres operar como si de una única reserva se tratase, habilitando mayores emisiones de moneda papel y una bajada notable de los tipos de interés, incluida la tasa de descuento. Máxime en épocas de escasez de oro - por ejemplo, en momentos de mayor actividad e intercambio en la economía india- o, como elemento de respuesta, de fuerte acaparamiento del metal, que obligaban al Gobierno indio a importar oro y plata de Londres a costes elevados y tasas de cambio muy desfavorables para la moneda india (papel o moneda-reserva). De modo que la configuración de un banco central en la India que pudiese disponer conjuntamente tanto de los saldos del gobierno como de las reservas de metal y de papel dispersas por el sistema bancario, así como gestionar y administrar a través de dichas reservas el papel moneda en circulación, permitiría que la India pudiese afrontar las crisis económicas con más éxito y celeridad, gracias a la posibilidad de aumentos discrecionales en la oferta monetaria.

En obras posteriores y paulatinamente, Keynes fue desechando la idea de cualquier sistema de patrón metálico de valor y cambio como forma de controlar la estabilidad del valor del dinero, a la par que culpaba al patrón oro, y su retorno en 1925 en la mayor parte de Europa y países con comercio desarrollado, de fomentar una fuerte depresión económica, defendiendo un control monetario discrecional y con cierta flexibilidad por parte de las autoridades. Aunque nada que se salga del teórico cuantitativo intervencionista, descrito previamente.

\subsection{The economic consequences of the peace (1919)}

Fruto de su frustración como representante del Tesoro Británico en la Conferencia de Paz de París, de 1919, este acertado libro denuncia el desatino planeado y materializado por los aliados al tratar de imponer a Alemania unos pagos en concepto de indemnización de guerra que, simplemente, no podían atenderse de forma razonable y cuya exigencia, preveía Keynes,

25 Sobre todo, tras varias décadas desarrollando un especial aprecio por el oro, en contra de la plata, que había favorecido su creciente atesoramiento en la India (Keynes 1971a, 52-59). 
destruiría los mecanismos económicos en los que se había basado la prosperidad europea previa a la Gran Guerra, pudiendo provocar el establecimiento de una dictadura (populismo) y una nueva guerra, como venganza por parte de Alemania. Cosa que sucedió.

Aparte del argumento, que Keynes exhibió con fuerza, de que los aliados habían incumplido de manera flagrante varios compromisos del Tratado de Armisticio que garantizaban cierta equidad y justicia en los acuerdos sobre pagos por reparaciones, ajustes territoriales y especialmente, imparcialidad en materia económica, Keynes menciona, particularmente, los problemas inflacionistas que causarían los gobiernos con la impresión de billetes para hacer frente a sus deudas, o simplemente obtener los recursos necesarios para la reconstrucción, dada su timidez o incapacidad para aumentar los impuestos. Y también señala la estrechez de miras exhibida por los aliados ante el desacuerdo para establecer un sistema de préstamos internacionales para toda Europa, que proveerían los Estados Unidos, pero que el presidente Wilson descartó desde un principio. Asimismo, y sobre la base del mismo armazón cuantitativista, detalló la relación existente entre los déficits excesivos y el creciente endeudamiento del gobierno alemán con la aparición y desarrollo del proceso inflacionista que ya empezaba a producirse en 1919 y que se desarrollaría hasta finales de $1923^{26}$.

Añade a ello Keynes el gran error de creer que los controles de precios - y la persecución del agiotista- pueden ser una solución o salida a los problemas planteados, puesto que, usando una licencia marxista, tales regulaciones "contiene[n] en sí mismo[as] las semillas de la decadencia económica final, y en última instancia seca[n] las fuentes de suministro u oferta final" (Keynes 1971b, 151). Con todo, Keynes mantiene su constante intervencionista dentro del argumento ortodoxo del libro: los tiempos han cambiado y los mercados no funcionan correctamente, específicamente los del ahorro e inversión, por lo que el capitalismo debe ser controlado ${ }^{27}$.

\subsection{A tract on monetary reform (1923)}

Con un claro y marcado enfoque cuantitativista y alto nivel analítico, Keynes aborda en este libro el problema de la crisis económica, donde los factores monetarios y financieros - incluido, siguiendo a Marshall, el papel catalizador y de transmisión que ejercen las instituciones financieras, bolsas de valores incluidas- son claves en la explicación y comprensión de las crisis y fluctuaciones del crédito, pero, a su vez, y desde su posición intervencionista, dichos factores se convierten, en manos de la autoridad, en los mecanis- mos o instrumentos principales y más efectivos para prevenirlas o resolverlas. Ni el Tract (1923), ni tampoco el Treatise (1930), muestran un Keynes particularmente innovador en este sentido, pero ambas obras ponen de manifiesto su desenvoltura y experiencia en asuntos monetarios y financieros.

El problema fundamental en el Tract es la estabilidad de precios, ya que, afirma Keynes, tanto la inflación como la deflación son los grandes males de la economía que producen graves perturbaciones sobre las expectativas más sólidas de inversionistas, empresarios y asalariados. Esta visión equilibrada de los perjuicios ocasionados tanto por la inflación como por la deflación para la economía y sus agentes se irá tornando, con los años, en un juicio asimétrico favorable para la inflación y contrario con la deflación, sobre sus efectos y consecuencias o en la urgencia de su remedio.

El argumento desarrollado por Keynes en el Tract es que, dado que los objetivos de estabilización de precios y mantenimiento de una paridad con el oro o fijación del tipo de cambio de la libra esterlina con otras monedas extranjeras, que al estar referidas al oro o ser convertibles vendría a ser lo mismo, pueden ser incompatibles por los movimientos en el valor del metal precioso, debe optarse por una moneda fiduciaria y manejada - controlada - por la autoridad monetaria correspondiente.

El patrón oro o cualquier garantía gubernamental de convertibilidad, así como cualquier otro sistema de cambios fijo, cuyo objeto declarado sea lograr la estabilidad del valor externo de la moneda (libra esterlina) debe sacrificarse en aras del logro de la estabilidad de precios interna. Estabilidad que, a su vez, sólo se logrará mediante la eliminación del patrón oro y la implantación de una moneda fiduciaria cuya cantidad (oferta) quede bajo control de un banco central monopolista que actúe a través de la tasa bancaria de interés, como mecanismo intermedio, para lograr el control del nivel de precios interno, fundamental para la economía. Por tanto, si el gobierno debía decidir entre una devaluación y una deflación, y dado que la eficiencia y hasta la propia supervivencia del capitalismo podían ponerse a prueba sin la existencia o consecución de un nivel de precios estable, Keynes no vacilaba en defender la devaluación en lugar de la deflación. A lo que añade el rechazo de una regla monetaria o ajustes semiautomáticos y preestablecidos, como fórmula inapropiada de política monetaria para el control del ciclo económico, y la defensa del manejo discrecional de la oferta monetaria.

Su defensa acérrima del control de precios y la estabilidad en el valor o poder adquisitivo del dinero se fundamenta y justifica teóricamente en el Tract

\footnotetext{
Calcula Keynes que el total de gasto por reparaciones son unos $£ 25.000$ millones, de los que no más de $£ 10.000$ millones se cubren mediante los ingresos impositivos, y todo ello sin considerar los pagos por indemnización estipulados en el Tratado (Keynes 1971b, 101-106 y 106-131).

27 Véase Rodríguez Braun 2006, 375. Es en esta obra donde Keynes cita la supuesta frase de Lenin de que "la mejor forma de destruir el sistema capitalista sería corromper la moneda." (Keynes 1971b, 148). Por otro lado, Keynes erró en sus predicciones sobre la evolución de las economías alemana y europea y las posibilidades de producción de hierro, acero o carbón presentadas en su libro. Véase Mantoux (1946), sobre todo las estadísticas ofrecidas a partir de la página 70 en adelante y 162 y ss.
} 
(1923) mediante la versión de la teoría cuantitativa de Cambridge, siguiendo la tradición recibida de Alfred Marshall, según la cual el valor del dinero viene dado por su oferta y demanda. Demanda de dinero que expresa según la ecuación de los saldos de caja, donde la proporción que los individuos mantienen en forma de saldos líquidos reales, tanto en efectivo como en depósitos bancarios, no es constante ni un parámetro del modelo, sino que depende de diversos factores o variables tales como el tipo de interés, las expectativas en general, el nivel de desarrollo comercial y financiero de una economía, las mejoras tecnológicas y de organización en general o la distribución de la renta, entre otras variables ${ }^{28}$.

Asimismo, el diagnóstico del Tract sobre las fluctuaciones económicas y su análisis de cómo los movimientos monetarios o del crédito intensifican - cuando no originan - los procesos de crisis económicas están en la más pura tradición marshalliana. Marshall y sus seguidores habían destacado los males de las fluctuaciones de precios y la importancia de la estabilidad del valor del dinero, junto con los problemas a más largo plazo de las fluctuaciones económicas ocasionadas por los movimientos del crédito. Precisamente a través de los factores o variables considerados en la demanda de dinero, como tipos de interés y expectativas, Marshall puso especial énfasis en la incertidumbre que crean, y las especulaciones que introducen, las fluctuaciones de precios en la vida económica, añadiendo como un mecanismo importante de todo el proceso la rigidez experimentada por los salarios nominales o monetarios, que dificulta o impide el reajuste del sistema económico ${ }^{29}$.

Para Keynes existía, además, otra buena razón por la que oponerse al patrón oro y la paridad de preguerra. Sostenía que el retorno a la convertibilidad de la libra esterlina en oro impedía manejar la moneda - y el tipo de cambio - conforme a las necesidades de la economía británica y, tal como estaban distribuidas las reservas de oro en la economía mundial tras la Primera Guerra Mundial -mayoritariamente en manos de los Estados Unidos-y tal como él esperaba que se distribuyesen dichas reservas en un futuro, la convertibilidad suponía ceder de facto el control de precios y tipos a la Junta de la Reserva Federal, en Washington, lo que era humillante y deshonroso para un británico victoriano y elitista como Keynes.

Para colmo, hacerlo a la paridad de preguerra con el dólar suponía revaluar la libra esterlina brutalmente, puesto que la economía británica había experimentado una fuerte inflación antes y durante el conflicto. Es decir, suponía devaluar fuertemente la economía británica, todos los precios y entre ellos los salarios; pero como había una tendencia, aceptada históricamente, de inflexibilidad del mercado laboral al ajuste vía precios (salarios) que, además, se había intensificado bajo unas condiciones más modernas de contratación laboral, con un papel creciente de los sindicatos, tal política deflacionista supondría, de hecho, una contracción brusca del empleo y la actividad, lo que fue exactamente el caso en los siguientes años $^{30}$.

Skidelsky $(1998,52)$ se equivoca interpretando tal razonamiento como un preludio implícito de que para Keynes el coste del trabajo (salarios) pasaba a ser la principal influencia del nivel de precios. En absoluto se precisa tener una teoría de la inflación basada en los salarios - cosa que sí defenderá en su obra de 1936- para establecer el razonamiento anterior, pues, como he explicado, todo este análisis de 1923 se mantiene en la más pura ortodoxia cuantitativa. Sí debe admitirse, sin embargo, que Keynes percibió claramente, y así lo expuso, que una moneda sobreevaluada no siempre es sinónimo de una moneda fuerte y bien puede significar una moneda débil.

\section{4. "The economic consequences of $\mathrm{Mr}$. Churchill" (1925)}

Se trata de su lamento y rapapolvo por la decisión del Gobierno británico de retornar al patrón oro y hacerlo, para colmo, a la paridad de preguerra, pese a las ilustrativas y perjudiciales experiencias históricas al respecto. ${ }^{31}$ Tal posición no es contraria a,

${ }_{28}$ Este análisis de Keynes lo distancia de la versión simple, rígida o tautológica, que limita el dinero prácticamente a su función de cambio, con que parodió o ridiculizó la teoría cuantitativa en 1936.

En su estudio sobre la relación existente entre cantidad de dinero y nivel general de precios, desarrollado en el Tract, acepta Keynes que una versión simplista y proporcional de la teoría cuantitativa — que implica plena neutralidad del dinero— puede ser cierta a largo plazo. "Pero este largo plazo es una guía confusa para la coyuntura. A largo plazo estamos todos muertos. Los economistas se plantean una labor demasiado fácil y demasiado inútil si, en época de tempestades, tan sólo pueden asegurarnos que cuando pase de largo la tormenta las aguas volverán a la calma" (Keynes 1923, 80; en versión española 1992, 95. Cursivas en el original). Destaco que Keynes determina que se trata de una situación o un caso extremo en la interpretación de la teoría cuantitativa que, como vengo insistiendo, no es la predominante ni la que siguen los principales autores cuantitativistas desde Richard Cantillon. Más bien, la simpleza de que dinero y precios se mueven con cierta inmediatez y proporcionalmente, y que, por tanto, la demanda de dinero no se altera con los factores señalados y sólo tiene sentido por su motivo de transacción, es una interpretación trivial y tosca de la teoría cuantitativa sostenida por sus detractores, incluido el propio Keynes en la TG.

29 Como he señalado en Méndez Ibisate 1993a, 359-60 y n. 73 y en Méndez Ibisate 2000, 37-42, Keynes no es el inventor o innovador de la inclusión de rigideces en los mecanismos de análisis de las fluctuaciones económicas o del crédito. Aunque no lo cita, la rigidez de salarios era conocida, aceptada y utilizada por los clásicos, y él la aprende de Marshall (por ejemplo, Marshall 1887, 191-2). Tampoco son de Keynes, ni keynesianas, las peculiares rigideces o fricciones existentes en el mercado laboral o en la formación de precios (salarios) y cantidades en dicho mercado, que pueden rastrearse hasta Cantillon o Adam Smith.

30 Tras la restauración, en 1925, del patrón oro a la antigua paridad de preguerra, por parte del ministro de Hacienda (Chancellor of the Exchequer) Winston Churchill, Keynes escribe su ensayo Las consecuencias económicas del Sr. Churchill. Además, los problemas de la industria británica para crear empleo, que consideró estructurales, le llevaron a escribir El final del laissez-faire (1926).

31 Una situación similar se experimentó con el retorno al patrón oro en 1819-21, también a la paridad de preguerra siguiendo las tesis de David Ricardo. Véase Méndez Ibisate (1988b). 
ni lo aleja un ápice de, mantener un análisis teórico cuantitativista aunque, para lograr persuadir aún más al público sobre la necesidad de intervenir el sistema y otorgar más arbitrariedad a las autoridades monetarias, Keynes presentase los efectos deflación, problemas de liquidez y crédito y freno de la actividad - como un resultado pernicioso del patrón oro en sí mismo, dado el empecinamiento, según él, de las autoridades británicas en adoptar una política monetaria - y económica- excesiva y tenazmente ortodoxa.

"Las consecuencias económicas de Mr. Churchill", publicadas como artículos en el Evening Standard, del 22 al 24 de julio de 1925, se recopilan en sus Essays in Persuasion (1931). El argumento principal de Keynes en este opúsculo para oponerse al retorno del patrón oro se basa esencialmente en la elección de una paridad inadecuada, la de preguerra, que obviaba la inflación acontecida a lo largo del conflicto bélico por motivos de su financiación, y que era la auténtica causante de las distorsiones y males revelados y analizados $^{32}$.

En el Tract (1923), Keynes ya había expuesto "argumentos contra el patrón oro como tal", por lo que su análisis se centra aquí en el hecho de haber restablecido una paridad de la libra papel con la libra oro de preguerra, sin considerar la inflación interna - precios y costes muy por encima de lo que la nueva paridad recogía o representaba - acaecida como consecuencia de la Primera Guerra Mundial (Keynes 1972, 212). Tal decisión, sostiene, forzará a producir una contracción intensa y cuantiosa de precios (devaluación interna) que, según él, equivaldrá en proporción a la revaluación de la moneda papel instaurada por la antigua paridad de cambio, olvidando que no siempre las elasticidades son iguales a uno - por ejemplo, en los efectos que, según expone, tendrá todo el proceso sobre las industrias importadoras y exportadoras británicas - y obviando en varias partes de su argumentación que, en la transmisión de efectos intermedios que tienen lugar durante el ajuste, primero tras la revaluación de la libra papel y luego tras la deflación de la economía, pueden ampliarse o perderse por el camino resultados y que no siempre todos los agentes retornan a sus posiciones de partida, pese a dichos ajustes ${ }^{33}$.

Pese a la decepción que le supuso tal retorno al patrón oro, máxime tras sus esfuerzos por persuadir de lo contrario a mandatarios y sociedad británicos, Keynes confía todavía, en este ensayo, en la capa- cidad de las autoridades y de la política monetaria para arreglar los problemas que trata. Sobre todo, el problema principal de un desempleo creciente, promovido por dicha medida, que impone ajustes de devaluación interna y un proceso de restricción del crédito por parte del Banco de Inglaterra para forzar tal deflación de precios y costes que, a la vez, es a todas luces contraproducente para la situación y problemas reales de la economía británica ${ }^{34}$.

Puesto que el retorno al sistema de patrón oro al cambio de preguerra había revaluado sobremanera la libra papel, sólo había dos formas de retornar al valor que el mercado solicitaba entre ambas monedas tras la inflación acontecida - siendo el argumento frente al dólar el mismo-. Una era la escogida por el Gobierno y las autoridades oficiales, de dejar actuar a las fuerzas del mercado para que los precios - $y$ costes - se contrajeran de forma equivalente, con la consiguiente reducción de la actividad económica y del empleo. Por su parte, y como alternativa, Keynes insiste en reducir los tipos de descuento del Banco de Inglaterra y perseguir una política que facilite y amplíe el crédito, proveyendo de liquidez al comercio y la industria británicos. Es decir, en lugar de ajustar vía deflación de precios, lo cual — señala- es doloroso para los trabajadores y los empresarios más débiles, se trata de forzar una devaluación de la libra papel, mediante sobreemisión, para imponer un cambio entre el papel y el oro más ajustado al existente tras la Gran Guerra, considerando la inflación producida.

En todo caso, y siguiendo el soporte analítico cuantitativista, la aparición de un paro masivo en los años veinte llevó a Keynes a atribuir sus causas a errores precedentes de las autoridades monetarias que, en torno a 1919-1920, se habían resistido a elevar de forma decidida, suficiente y a tiempo el tipo de descuento, permitiendo que el choque inflacionario de esos años, y los previos a la Guerra, se les fuese de las manos. Luego, y durante el período subsiguiente de reducción de precios, seguido de caídas en la actividad y el empleo, la misma inacción de las autoridades monetarias habría procurado, según Keynes, una sobrerreacción de la economía por haber mantenido tasas reales de interés excesiva o inadecuadamente altas, profundizando la recesión más de lo necesario. Keynes consideraba que esta segunda parte de tal política tenía como doble objetivo eliminar la inflación generada durante y después de la contienda bélica (para colmo, estimulada erróneamente con los acuerdos de Paz de Versalles), objetivo que él compartía;

\footnotetext{
En "Las consecuencias económicas de Mr. Churchill", Keynes rechaza desde el principio cualquier posibilidad de falta de demanda, interna o internacional, como causa de la crisis de actividad y desempleo que observa en la economía británica de esos años y que menciona específicamente para el caso del carbón y, por contagio, en el hierro y el acero. Véase Keynes 1972, 207 y 220-224.

33 Por ejemplo, Keynes 1972, 213-214. A pesar de esta crítica, Keynes indica en varias ocasiones que los ajustes necesarios no se siguen automáticamente, señalando que el mercado mantiene ciertas fricciones, e incluso llega a echar mano de rigideces o retardos en los ajustes de precios, particularmente de los salarios.

34 En realidad, Churchill se pensó mucho la decisión. Ordenó diversos y detallados informes al respecto antes de tomarla, contrastó opiniones enfrentadas e intentó posponerla hasta el final. Con el tiempo, admitió que fue uno de sus mayores errores. Keynes dice al respecto: “¿Por qué hizo una cosa tan disparatada? En parte, quizá, porque no poseía un criterio intuitivo para evitarse la comisión de errores; en parte porque, falto de ese criterio intuitivo, ensordeció a causa de las voces clamorosas de las finanzas convencionales; y, sobre todo, porque fue muy mal asesorado por sus expertos.” (Keynes 1972, 212). Entre éstos estaba el gobernador del Banco de Inglaterra, Montagu Collet Norman.
} 
pero también tenía el propósito de rebajar el nivel de precios lo suficiente como para lograr devolver -forzadamente- la convertibilidad de la libra con el oro a la paridad de preguerra y establecer el mismo tipo de cambio con el dólar $(1 £=4,86 \$)$ previo a la conflagración; algo que Maynard rechazaba de pleno.

\subsection{A treatise on money (1930 y 1931)}

La persistencia de problemas económicos, como el desempleo y la caída de la actividad, así como de inestabilidades en los procesos de ajuste en las fluctuaciones comerciales o del crédito, confirmaron a Keynes en su aversión hacia el patrón oro del que, desde el Indian (1913), desconfía y critica su falta de regulación e intervención por las autoridades, pero que en el Tract (1923) considera sin ambages "una reliquia bárbara"... "una reliquia de los tiempos en que los gobiernos eran en estas cuestiones menos fiables de lo que son ahora"35. El Treatise (1930) lo apuntala, más que como fuente de distorsiones, como una perturbación o impedimento en sí mismo.

Como en el Tract (1923), la inestabilidad del sistema de precios $\mathrm{y}$, por tanto, los procesos de inflación y deflación siguen siendo el tema central, junto con las fluctuaciones del crédito y económicas que los producen. Pero en el Treatise (1930) la variabilidad del nivel general de precios se explica por los desequilibrios, desajustes o desigualdades producidos en la relación entre el ahorro y la inversión.

La proposición teórica fundamental del Treatise, dice Skidelsky $(1998,106)$, es que ahorro e inversión son decisiones que se realizan o ejecutan por grupos diferentes de agentes, movidos por motivos diferentes y con expectativas distintas (ahorradores y consumidores; inversores o empresarios y bancos). Y Keynes sostiene que, en una economía monetaria, no existe ningún mecanismo automático que permita su conexión o igualación, por lo que únicamente la política monetaria puede y debe actuar como equilibrador.

Keynes considera que lo que el público desea ahorrar y lo que los bancos pueden prestar puede influirse o conducirse mediante el manejo del tipo de interés, de manera que la política monetaria permita alcanzar un equilibrio entre los préstamos bancarios y el ahorro, precisamente a través de la relación entre dinero bancario y ahorro. Así, aunque el ciclo económico sea un ciclo real relacionado con desajustes de la inversión -ocasionados por las oscilaciones en la rentabilidad real esperada de los bienes de capital-, dicho ciclo tiene plena conexión con el ciclo del crédito dado que los factores monetarios (sobre todo el dinero bancario) ampliarán, si no ocasionan, las fases de auge o depresión experimentados en el proceso ${ }^{36}$.

Siguiendo una tradición de la teoría cuantitativa cuyo principal y más evolucionado desarrollo provenía del economista sueco Knut Wicksell (1851-1926), las diferencias entre ahorro e inversión, generadoras de las fluctuaciones en la actividad y los precios, vienen explicadas en el Treatise por las diferencias entre la tasa natural o real (también tasa a largo plazo) y la tasa monetaria de tipos de interés, determinada en el mercado monetario o de préstamos bancarios. Cuando la tasa real o, como la denominó Wicksell, natural se sitúa por encima de la tasa monetaria de interés se producen incentivos y mecanismos que hacen que la inversión crezca por encima del ahorro, causando alzas en la demanda agregada de la economía que tienden a mover los precios al alza y generar procesos de expansión o burbujas. Y, viceversa, si la tasa monetaria o de préstamos de dinero se encuentra por encima de la tasa real o natural de interés, la inversión terminará situándose por debajo del ahorro, deprimiendo la demanda agregada de la economía y ocasionando una fase de crisis y depresión con deflación de precios. En todo el proceso $-\mathrm{y}$ para ambos casos - intervienen sistemas complejos de expansión o contracción del crédito, influidos también por alteraciones en las expectativas, junto con variaciones en la demanda de dinero inducidas por los tipos de interés y los movimientos de los precios que, a su vez, responden a los estímulos de mayor o menor gasto (mecanismos directo e indirecto de transmisión de efectos).

Tanto el análisis como los mecanismos utilizados eran familiares a Keynes, pues Wicksell los había expuesto en su obra Interest and Prices, publicada originalmente en 1898 y traducida en 1936 a instancias de R. F. Kahn y el propio J. M. Keynes ${ }^{37}$. Pero en el Treatise, Keynes lleva algo más allá el desequilibrio entre el ahorro y la inversión de lo que subsiste en el modelo cuantitativista wickselliano, que permite reajustes del mercado - ahorro e inversión - tanto a partir de los propios mecanismos internos (cuasiautomáticos) puestos en marcha por los procesos de expansión, burbuja, estallido y crisis, como a partir de la intervención directa de las autoridades, sobre todo

35 Keynes 1923, 172 y Keynes 1971a, 51. Resulta interesante y paradójica la constatación de Skidelsky, que afirma que "Keynes rechazó el patrón oro como un régimen apropiado" (Skidelsky 1998, 51), pero al mismo tiempo, en el marco de la constitución de un sistema financiero internacional, acepta que "Sus sucesivos planes para unas monedas administradas hasta Bretton Woods mantuvieron pese a todo un papel de «monarca constitucional» para el oro, como base de un sistema de tipos de cambio semifijos y como un guardián en última instancia contra la inflación." (Skidelsky 1998, 92. Cursiva mía).

36 Aunque en esencia marshalliano, el razonamiento de Keynes estuvo influido por Dennis Robertson; Sin embargo, su estructura argumental se encuentra descrita y desarrollada en la tradición de la teoría monetaria cuantitativa, mediante el uso del mecanismo indirecto, y Alfred Marshall lo expone con nitidez. Pero el análisis también roza algunos de los argumentos de la teoría del ciclo de economistas austríacos, como Hayek o su maestro Mises. Sabemos que Marshall mantuvo contactos con los austríacos en sus viajes al Tirol, aunque sus desacuerdos eran manifiestos. Véase Groenewegen 1995, 473-479 y 777-778.

37 El mismo análisis y razonamiento aparece también en el segundo volumen de las Lectures on Political Economy de Wicksell, dedicado al dinero (Money), publicado en 1906 y traducido en 1935 igualmente por iniciativa de Kahn, Keynes y L. Robbins. 
política monetaria, mediante el manejo oportuno de los tipos de interés para ajustar el ciclo. El Treatise se posiciona exclusivamente en esta segunda opción: no acepta mecanismos de reajuste - a través de los precios - entre demanda y oferta agregadas, lo que prolonga sin límites la depresión salvo que intervengan de forma discrecional, pero adecuada, las autoridades monetarias.

A este respecto, la existencia o adopción del patrón oro, al fin y al cabo una regla estricta, ataba las manos del Banco de Inglaterra para actuar y establecer una tasa de interés monetaria suficientemente baja como para lograr incentivar el nivel de inversión y hacer que se igualase con lo que la comunidad deseaba ahorrar, lo que explicaba el paro masivo sufrido por Gran Bretaña durante el período analizado ${ }^{38}$. Así, una vez más, Keynes propugna la supresión del patrón oro que impide a las autoridades manejar los tipos de interés a largo plazo, derivados en parte de tal decisión y tipo de convertibilidad establecido, y adecuarlos tanto a las necesidades de empresarios y ahorradores como a los costes internos de producción o a las necesidades de la balanza comercial. De hecho, Keynes mantiene su argumentación de 1925 y explica que la vuelta al patrón oro a la paridad de preguerra había sobrevaluado excesivamente la libra esterlina, estrechando el superávit de exportaciones disponible para la inversión en el exterior; y, al mismo tiempo, por exigencias de la convertibilidad, había impuesto una elevada tasa de interés bancario que reducía la inversión nacional, provocando que la inversión total se situase por debajo del ahorro preciso para mantener el pleno empleo. Y todo ello sin una reducción correspondiente de los costes de producción. De ahí, las pérdidas empresariales y el paro.

La cuestión realmente examinada en el Treatise no es tanto ya si mantener o no estable el nivel general de precios interno, objetivo que Keynes — todavía cuantitativista- da por descontado, como qué nivel de precios era el que habría que mantener para garantizar la estabilidad; es decir, qué nivel general de precios lograba una cierta estabilidad de equilibrio entre el ahorro y la inversión, que a su vez evitase tanto los procesos inflacionistas o deflacionistas como las fluctuaciones de la actividad y el desempleo.

Para ello, y puesto que las variaciones o desajustes de la tasa "natural" de interés —impulsadas por expectativas volátiles - respecto de la tasa monetaria o de mercado - determinada por las prácticas bancarias - explican las fluctuaciones, Keynes recomienda que las autoridades monetarias respondan de forma activa mediante actuaciones sobre la tasa de interés bancaria, atribuyendo una clara función anticíclica a la política monetaria ${ }^{39}$. Con la diferencia, respecto del Tract, de que en el Treatise la tasa bancaria procura actuar no sobre la base monetaria del sistema o la cantidad de dinero, sino sobre el tipo de interés a largo plazo o tasa real (natural) de interés, de la que dependen la oferta de ahorro y la demanda de inversión. Su presentación en el Treatise de una demanda de dinero algo más compleja, que la aproxima mucho a la teoría de la preferencia de la liquidez expuesta en la Teoría General (1936), permite que los movimientos en el tipo de interés afecten también a la demanda de dinero, habilitando la ruptura de la transmisión sistemática de efectos desde el tipo de interés hacia la cantidad de dinero (disponibilidades líquidas) y los precios, y facilitando la tarea de las autoridades monetarias ${ }^{40}$.

El objetivo de la autoridad monetaria era, por tanto, adaptar en cada momento el tipo de interés del mercado monetario (fondos prestables) al tipo de interés natural; pero, en caso de necesidad y si el manejo del tipo bancario no bastaba para lograr las variaciones deseadas en el tipo de interés monetario, Keynes proponía recurrir a operaciones de mercado abierto en valores; es decir, utilizar expansiones monetarias para reducir el desempleo, lo que se lograba a través de su influencia en los precios y los beneficios.

A pesar del aroma de preludio que el Treatise (1930) destila sobre la Teoría general (1936), las diferencias entre ambas obras son remarcables y señaladas por Keynes en esta última ${ }^{41}$. Tanto la eficacia como la esperanza depositada en la política mone-

\footnotetext{
38 Pese a las inevitables evocaciones o analogías con su TG, toda comparación o relación de este análisis con los posibles desajustes —insuficiencia — de la demanda agregada, especialmente por el lado de la inversión, expuestos en la Teoría general, es vacua e inútil. El propio Keynes lo advierte con insistencia y nitidez en su obra de 1936. Mientras que en el Treatise (1930) la igualdad entre la inversión y el ahorro se expone y trata como condición del equilibrio, en la Teoría general (1936) es un resultado del modelo ya que la renta o producción agregada actúa como variable de ajuste entre el ahorro y la inversión, forzando su igualdad hasta condiciones prácticas de identidad poco congruentes, si no contradictorias, con su ataque y anulación de la Ley de Say en la sección VI del capítulo 2. La inexistencia en el Treatise de este ajuste vía renta obliga a Keynes —y al sistema económico, tal como lo concibe- a poner todo el peso del remedio, de forma plena y exclusiva, en manos del banco central a través de la manipulación del tipo de interés como variable intermedia de política monetaria. Remedio inútil en la TG.

39 Tal papel anticíclico de la política monetaria, e incluso el uso del tipo bancario o de descuento como instrumento, se habían anticipado por Thornton (1802 y 1811) y J.S. Mill (1848). Véase, por ejemplo, Méndez Ibisate (1988b y 2000).

40 Véase Rojo 1984, 130-133. Pero nada de esta argumentación se aparta de la teoría cuantitativa del dinero, ni del análisis sobre la demanda de dinero o los mecanismos y efectos conocidos. De hecho, Keynes razona y analiza en el Treatise que los precios de los bienes se incrementan en la misma dirección que la variación en la cantidad adicional de dinero tras una bajada de la tasa monetaria de interés (Keynes 1971c, 183-184 y 187). Pero los aumentos en los precios no son proporcionales a la cantidad de dinero, admitiendo que la estructura de precios relativos también se modifica (Keynes 1971c, 235-238). Y ya había presentado como un caso peculiar, y más teórico que efectivo, la relación proporcional usualmente atribuida a la teoría cuantitativa: "en equilibrio... existe una relación única entre la cantidad de dinero y el nivel de precios de los bienes de consumo y la producción total, de tal carácter que si la cantidad de dinero se duplicase, los niveles de precios también lo harían.

Pero esta sencilla y directa relación cuantitativa es un fenómeno único del equilibrio tal como se definió antes.” (Keynes 1971c, 132).

41 Como apunto en la n. 38 supra, Keynes subraya diferencias entre ambas obras sobre conceptos, uso y variaciones, entre otros, de ahorro e inversión (por ejemplo, Keynes 1973, 60-61 y 77-80); demanda de dinero o preferencia por la liquidez y motivo especulativo (Keynes 1973, 173-174); o tasa natural y tasa neutral de interés (Keynes 1973, 242-244).
} 
taria desaparecen en 1936. Por supuesto, la TG también abandona el uso del mecanismo wickselliano para explicar las fluctuaciones de precios y los ciclos del crédito o económicos. Pero es que en la Teoría general las fluctuaciones de precios se esfuman del centro del escenario, que ahora queda ocupado por la depresión de la producción - encargada de igualar ahorro e inversión-y el empleo. Ahora será la renta, la producción - determinada, no se olvide, por la demanda agregada efectiva-, el mecanismo de ajuste - más bien desajuste- que permita acomodar los procesos de contracción de la economía, logrando alcanzar un cierto equilibrio, peculiar y diferente en su noción respecto del clásico, con niveles de empleo y producción inferiores a los que vaciarían el mercado (equilibrio con desempleo).

\section{Keynes renegado: la teoría cuantitativa, ¿caso particular o un imposible?}

Dado que en otros trabajos he desarrollado de forma crítica las ideas y postulados de la Teoría general ${ }^{42}$, me centro aquí en sus teorías y propuestas monetarias y el abandono de sus posiciones cuantitativistas y los principios neoclásicos monetarios recibidos.

Cuando Keynes publica en 1936 la Teoría General del Empleo, el Interés y el Dinero, su popularidad, reputación e influencia, provenientes de sus anteriores escritos, eran sobrados y acreditados. Pero la TG le otorgará un reconocimiento exclusivo y un lugar privilegiado en la Historia del Pensamiento Económico, que creará una escuela de pensamiento propia.

Su ruptura con el armazón teórico cuantitativista es total dado que, desde el principio, plantea una teoría de la inflación basada en los costes de producción, concretamente en los salarios, especificando que la inflación de demanda, tan utilizada como argumento por el keynesianismo posterior, es un caso particular y anómalo en la TG, ya que se trataría de una situación, hipotética más que real, en la que todos los recursos están ocupados y cualquier impulso añadido en la inversión o el consumo elevarían no la ocupación sino los precios. Algo impensable en el modelo y argumentación teóricos del libro, que considera el pleno empleo una quimera inalcanzable. Pero, además, establece que, mediante la conjunción de la oferta y la demanda de dinero, el mercado monetario determina el tipo de interés y no el poder adquisitivo del dinero o su capacidad real de compra, convirtiendo erróneamente el tipo de interés en un concepto y fenómeno monetario, completamente alejado de la teoría de fondos prestables, como expongo en Méndez Ibisate (2006, 2, 5, ns. 11, 17, 19, 26-27; y 2012, 40, 59, n. 47 y, en general, la sección 5.2) ${ }^{43}$.

Recupera e implanta Keynes la vieja y errónea idea de que el tipo de interés es el valor o precio del dinero - lo es del tiempo- - Y es que al hacer depender el ahorro de la renta, para su ajuste con la inversión, extrae del mercado de fondos prestables la determinación del tipo de interés, llevándola al mercado monetario, e instaura en aquél la determinación, en parte, de la renta; una renta que permite equilibrar ahorro e inversión, pero que prácticamente es imposible que lo haga al nivel de pleno empleo o vaciado de mercado dado que la renta o nivel de ingreso se determina mediante la demanda efectiva, que incluye también otros componentes que, a su vez, dependen de múltiples factores, entre los que se encuentran variables psicológicas que afectan a las decisiones de consumo, y por ende de ahorro; de inversión; de liquidez; y a la determinación de precios como salarios y tipos de interés ${ }^{44}$.

La determinación de la tasa de interés es importante porque forma parte de la condición de equilibrio que establece que la demanda de inversión no experimente impulsos al alza o a la baja: la igualación entre la eficiencia marginal del capital y el tipo de interés monetario. Keynes mismo se encarga de despejar cualquier duda sobre una posible similitud o relación de esa condición con la igualación entre la tasa de interés natural o real y la monetaria o del mercado de fondos prestables, utilizada en el Treatise ${ }^{45}$. Dado que la clave fundamental de la insuficiencia de demanda agregada proviene de la inversión privada, si, mediante la oportuna manipulación de las variables monetarias, las autoridades pudiesen reducir la tasa de interés lo suficiente como para lograr que la eficiencia marginal del capital la superase, se lograría impulsar la inversión y así compensar o suplir tal carencia de demanda. Pero Keynes dedica parte de la TG a explicar y demostrar que eso no es posible y que la política monetaria no funciona.

Contrariamente al argumento e idea generalizados, Keynes no sustenta tales opiniones en su mecanismo de la "trampa de liquidez", sino en las peculiares características del dinero asociadas a su cualidad de ser el activo líquido por excelencia. Tales propiedades del dinero, que generan rigidez de respuesta del tipo de interés ante

Véanse Méndez Ibisate (2006, 2012 y 2014b)

3 Keynes 1973, 167. Su abandono de la teoría cuantitativa como estructura analítica lógica de los movimientos, desajustes o fluctuaciones de la economía, y la búsqueda de una nueva argumentación y papel de la teoría y política monetarias en la TG, explican la adopción del principio de demanda efectiva y su impugnación de la Ley de Say. Véase Méndez Ibisate 2014b, apartado 3.

44 No sólo se trata de influencias psicológicas y de determinación de expectativas sobre valores futuros desconocidos e inciertos. El problema en sí es que los individuos, los agentes privados, son ignorantes y caprichosos y, a la hora de estimar o decidir en tales asuntos influidos por la psicología, forman sus expectativas no sobre cálculos lógicos estimados, matemáticos y con cierta racionalidad, sino sobre bases completamente arbitrarias, extravagantes, frívolas, volubles e imprevistas. Esto es especialmente cierto y grave en las decisiones de inversión privada, incluidas las inversiones financieras o bursátiles, que Keynes califica despectivamente como rentistas. Algo de ese desprecio hacia la función del rentista aparece ya en el capítulo 1 del Tract de 1923, aunque atenuado respecto de la TG.

45 Véase Méndez Ibisate 2012, $42-46$ y las referencias de Keynes, también en las notas a pie. Y Keynes 1973, capítulo 14 y $242-243$. 
variaciones o estímulos de la cantidad de dinero, son que el dinero tiene una elasticidad de producción nula o muy baja; que tiene una elasticidad de sustitución nula o muy baja y que sus costes de almacenamiento también son muy bajos ${ }^{46}$. Y como consecuencia, sobre todo de esta última característica, puede producirse el caso teórico e hipotético de la "trampa de liquidez", consistente en que las expectativas formadas sobre la tasa de interés, que "es un fenómeno altamente psicológico" (Keynes 1973, 202), inducen a creer que dicha tasa ha alcanzado un nivel suficientemente bajo como para que únicamente pueda esperarse su aumento, de modo que toda inyección de liquidez quedará absorbida por la demanda de dinero, fundamentalmente por aquella parte afectada por el tipo de interés, es decir, la demanda por motivo de especulación ${ }^{47}$.

Pero la rigidez e inoperancia del tipo de interés en política monetaria no provienen de la trampa de la liquidez, sino que son consecuencia de las mencionadas propiedades del dinero, que operan sin precisar la aparición de la susodicha trampa. Además, Keynes considera que tal eventualidad no es real o posible en su modelo, puesto que el nivel de la eficiencia marginal del capital es tan bajo que, para mantener la inversión y cubrir las necesidades de demanda, obligaría a rebajar la tasa de interés hasta niveles inaceptables para los prestamistas, pero también para el público en general y los prestatarios ${ }^{48}$. Simplemente, ni la economía, ni tampoco la política monetaria, podrán dar con la tasa de interés adecuada para mantener los impulsos de inversión, equivalente con una eficiencia marginal del capital que es demasiado baja y obedece a impulsos irracionales completamente subjetivos:
La agudeza y la peculiaridad de nuestros problemas derivan de la posibilidad de que la tasa media de interés que permitirá un nivel medio razonable de ocupación es tan inaceptable para los propietarios de riqueza, que no puede establecerse fácilmente por medio de simples manipulaciones de la cantidad de dinero ${ }^{49}$.

Que la demanda de dinero depende de variables como el tipo de interés y de factores de confianza, crédito (credibilidad) o imprevistos era sobradamente conocido por los economistas cuantitativistas hasta entonces, Keynes incluido. Pero la TG da un vuelco completo al análisis monetario, racionalizando la inoperancia de la política monetaria para sacar el sistema económico de una situación de crisis permanente, con infrautilización y desempleo de los recursos productivos - sobre todo trabajo- e insuficiencia (caída) de la actividad, y formulando la intervención directa de las autoridades sobre las decisiones de inversión así como el uso de herramientas fiscales para estimular tanto el consumo como las decisiones de inversión, o las expectativas a ellas asociadas, pero, sobre todo, los programas de gasto directo e indirecto por parte de administraciones públicas y gobiernos.

Además, cabe señalar algunas precisiones sobre la demanda de liquidez que traza Keynes en su TG y que no se corresponden con las interpretaciones y análisis al uso.

Aunque los desarrollos keynesianos y las controversias desde la segunda mitad del siglo XX han apuntalado que los motivos importantes o principales de demanda de dinero en la TG son los relacionados con aspectos especulativos, donde sobre todo influye

46 Un desarrollo y análisis de tales características, junto con la explicación de algunos de sus efectos en el armazón teórico de la TG, se exponen en Méndez Ibisate 2012, 72-80. El concepto, aunque no el término, de "trampa de liquidez" aparece desarrollado y analizado en la TG (Keynes 1973, 202-203 y 207), y se incorpora con prontitud al análisis keynesiano por Hicks en su artículo de 1937, "Keynes y los clásicos”, quien prefería denominarlo "trampa especulativa". Como señala también Hicks en otro artículo de 1957, continuador del anterior, "Otra vez los clásicos", el término "trampa de liquidez" fue acuñado por Dennis Robertson. No debe confundirse este fenómeno o situación particular de "preferencia virtualmente absoluta" de liquidez (Keynes 1973, 207) con la "preferencia de [o por la] liquidez", que es como se refiere Keynes, en general, a la demanda de dinero o liquidez, incluidos depósitos de diversa índole en instituciones bancarias o financieras — siguiendo todavía la tradición de Cambridge-

47 En la recesión iniciada en agosto de 2007, que en la UE se extiende hasta 2014, muchos analistas confundieron la respuesta general de los agentes privados de aumentar la demanda de dinero como refugio ante la enorme incertidumbre y el desplome de la confianza, el crédito y las expectativas (en algún momento muy difíciles de formar), con la aparición de una trampa de liquidez. En tal situación de incertidumbre y desconfianza, la mayor demanda de dinero en absoluto respondía a un incentivo especulativo, o a la expectativa de un futuro descenso de los valores financieros o bursátiles como respuesta a una prevista y casi segura alza del tipo de interés, para luego hacer beneficio con la subsiguiente subida de dichos valores. De hecho, los títulos y valores hacía tiempo que caían sin la supuesta reacción de compras especulativas por parte de los agentes, que presume la trampa de liquidez. El desconcierto e incertidumbre ante lo que ocurría era la clave, y su dimensión tal, que lo que se reclamaba era acabar con las pérdidas y desplomes, no agudizarlos. Los agentes privados emplearon, como pudieron, parte de la liquidez inyectada en pagar muchas de las deudas contraídas previamente; no en especular. La especulación estuvo del lado de Gobiernos y de las instituciones financieras, que actuaron en connivencia u obligación para colocar deuda pública. Véase Méndez Ibisate (2013). Además, los análisis postkeynesianos, desde Hicks (los citados de 1937 y 1957 o sus Critical Essays in Monetary Theory, de 1967) o Robertson (1940), Essays in Monetary Theory, coinciden en que la trampa de la liquidez sería un fenómeno a corto plazo, no aplicable al largo plazo, ya que el propio Keynes excluyó la posibilidad de mantener durante largo tiempo los tipos de interés muy bajos o por debajo de la eficiencia marginal del capital. Keynes habría quedado atónito de vivir en un mundo que durante tantos años (desde comienzos del siglo XXI, al menos) mantiene tipos de interés, reales y hasta nominales, en cero o negativos.

48 «Del porcentaje de ganancia, que la curva de la eficiencia marginal del capital permite al deudor esperar ganar, tiene que deducirse 1) el costo de poner en contacto a prestamistas y prestatarios, 2) el impuesto sobre el ingreso y los impuestos adicionales y 3) el margen que el prestamista requiere para cubrir su riesgo e incertidumbre, antes de llegar al rendimiento neto disponible... En condiciones de un promedio tolerable de ocupación, si este rendimiento neto resulta ser infinitesimal, los métodos tradicionales pueden ser infructuosos.» (Keynes 1973, 309). Para colmo, el nivel de la eficiencia marginal del capital es especialmente bajo en economías desarrolladas o muy capitalizadas, produciéndose la "paradoja de la pobreza en medio de la abundancia" (Keynes 1973, 30), ya que, con ingresos o rentas crecientes, la brecha de la demanda de consumo aumenta (consumo medio decrece) y la inversión debe cubrir un agujero cada vez mayor, pese a que el incentivo a invertir (eficiencia marginal del capital) es cada vez menor con la abundancia del capital. Así, "aunque este caso extremo [trampa de la liquidez] pueda llegar a tener importancia práctica en el futuro, aún no conozco ningún ejemplo de él” (Keynes 1973, 207).

49 Keynes 1973, 308-309. En otra parte asegura: "Por mi parte, soy ahora algo escéptico respecto al éxito de una política puramente monetaria dirigida a influir sobre la tasa de interés.” (Keynes 1973, 164). 
el tipo de interés, y el propio Keynes dedica buena parte del capítulo 13 de la TG a la defensa de tal idea, a la hora de justificar la forma decreciente de la curva de demanda de dinero respecto del interés Keynes basa su argumentación, sobre todo, en cómo afecta la tasa de interés a la demanda de dinero a través del ¡motivo de transacciones!, más asociado con la teoría cuantitativa, prevaleciendo analíticamente este motivo sobre el especulativo ${ }^{50}$.

Otra muestra de que el motivo transacciones y la demanda de dinero para intercambio imperan en la TG sobre el motivo especulativo es que, para demostrar la peculiaridad del dinero de tener una elasticidad de sustitución próxima a cero, Keynes sostiene que proviene de que la utilidad del dinero se deriva únicamente de su valor de cambio, y que ambos varían a la par; así, cuando el valor de cambio del dinero aumenta (deflación) no existe motivo ni incentivo a sustituirlo por cualquier otro factor o activo $^{51}$. En definitiva, en la TG, el motivo de transacciones o intercambios es tanto o más fundamental que el especulativo en los procesos y ajustes que tienen lugar a la hora de repercutir una inyección de liquidez sobre los tipos de interés, mediante su influencia en la demanda de dinero. Por lo que la inoperancia atribuida a la teoría cuantitativa y su abandono en la TG no se fundamentan, como suele suponerse, en un cambio de enfoque drástico sobre la demanda de dinero, que incidiese más en los aspectos especulativos, ya presentes en el cuantitativismo.

Además, otra novedad sobre el análisis usual es que los supuestos y características del dinero que recoge la TG significan una demanda de dinero mucho más estable de lo que los estudios ulteriores han conjeturado y otorgado a Keynes. Su argumentación o análisis para explicar la proximidad a cero de las elasticidades de producción y de sustitución del dinero permiten deducir que la demanda de dinero es más estable o, al menos, no tan inestable como plantearon las disputas monetaristas y keynesianas de la segunda mitad del siglo XX, aludidas en la sección dos ${ }^{52}$.

No obstante, aun con sus errores y contradicciones o ulteriores desvíos y licencias en su interpretación, la Teoría general supone una ruptura conceptual, analítica, argumentativa y de praxis de las autoridades monetarias respecto de la teoría cuantitativa, aceptada hasta entonces por Keynes, bien estructurada, que formula con precisión lo inadecuado e inútil de la política monetaria y el manejo del dinero para resolver los males que aquejan el sistema económico.
Aunque los problemas del mercado monetario sean importantes y de naturaleza similar a los que exhibe la eficiencia marginal del capital -psicológicos y de formación de expectativas-, la esencia del infortunio no es monetaria; el manejo del dinero, la política monetaria, nada logra o arregla de lo que ya está mal: insuficiencia de demanda efectiva, particularmente, en la demanda de inversión privada y sus componentes. Con todo, Keynes defiende, congruentemente con el mensaje del libro, la presencia y discrecionalidad de una autoridad monetaria centralizada (banco central) para el control del dinero y de la política monetaria ${ }^{53}$.

Pero lo que preocupa a Keynes y plantea en la TG no son procesos de fluctuaciones económicas o movimientos de auge y depresión del sistema de mercado, en donde pueda discutirse acerca de qué tipo de intervención es más o menos adecuada o si una política es más o menos efectiva o dañina que otra, según situación o circunstancias, como pudieran proponer o discutir entre sí los teóricos cuantitativistas, tanto los proclives al manejo de la economía como los menos intervencionistas, más inclinados a considerar que los mecanismos del mercado funcionan aunque no lo hagan "perfectamente".

Lo que busca Keynes explicar y analizar específicamente en la TG son las crisis y depresiones, pues considera que el sistema económico, dejado a sus meras fuerzas o leyes internas, conduce inexorablemente a una situación persistente o continuada de insuficiencia de demanda y, por tanto, de escasa producción u oferta y desocupación de los recursos productivos, sobre todo del trabajo, que sólo puede revertirse o manejarse desde una contundente, audaz y determinante intervención administrativa, centrada en el gasto público en general, incluso meramente derrochador como en el caso del enterramiento de botellas con billetes de banco (Keynes 1973, 129), aunque en ocasiones Keynes muestre cierta preferencia por el gasto público en inversión.

Por todo ello, y ante la inoperancia de las fuerzas propias del mercado para poder sacar a la economía de tal situación, siendo más bien que la conducen hacia ella, la TG de Keynes presenta más como una quimera que como un caso aislado o particular la idea de que los impulsos monetarios, las inyecciones de liquidez o las bajadas de tipos logren afectar al alza el nivel general de precios o que una política monetaria expansiva pueda llegar a ser operativa ${ }^{54}$.

\footnotetext{
50 Véase Keynes 1973, 171-172. Además, el motivo precaución, teóricamente también afectado por el tipo de interés (Keynes 1973, 196), lo está en menor medida, hasta el punto de admitir en su argumentación que este motivo precaución no es sensible al tipo de interés y depende del ingreso o renta.

Véase Méndez Ibisate 2012, 76 y n. 63. Keynes da importancia y trata el dinero como instrumento o activo de cambio, no de especulación.

Véase Méndez Ibisate 2012, 75 y 77 y todo el razonamiento presentado desde la página 73.

Véase Keynes 1973, 235 y 378.

Keynes plantea la teoría cuantitativa como un caso muy especial y raro (Keynes 1973, 304-306); y como una parodia o ridiculización de lo que él mismo defendió anteriormente (Keynes 1973, 208-209). Además, en la TG, la hipótesis de que un aumento de la inflación, haciendo disminuir la tasa de interés real $(\mathrm{r}-\pi)$ puede - al colocarse por debajo de la eficiencia marginal del capital—alentar la inversión y, por tanto, el empleo, no tiene sentido lógico (Keynes 1973, 141-143). Al contrario, "la expectativa de una caída futura en la tasa de interés tendrá por efecto hacer bajar la curva de la eficiencia marginal del capital; pues significa que la producción resultante del equipo hecho en la actualidad habrá de competir durante parte de su vida con la proveniente del equipo que se conforma con un rendimiento menor." (Keynes 1973, 143. Cursivas en el original). De modo que en
} 


\section{Conjeturas sobre un cambio drástico: a modo de conclusión}

El trabajo muestra una evolución en la teoría y política monetarias de J. M. Keynes y un giro drástico en su obra cumbre de 1936.

Desde sus comienzos hasta el Treatise de 1930, Keynes defiende, siguiendo a Marshall, una teoría monetarista o cuantitativa como base analítica de la búsqueda de la estabilidad del nivel general de precios (del valor del dinero) para luchar contra las fluctuaciones económicas. Problema que, a partir del retorno del patrón oro en 1925, irá centrando crecientemente en las depresiones y desocupación de recursos, agudizándolo en el Treatise, entendidas como consecuencias dentro de un análisis teórico cuantitativista.

En ese marco teórico, Keynes postula la intervención decidida y discrecional de la autoridad monetaria, aunque con ciertos cambios en sus recomendaciones y en los instrumentos de política monetaria: el uso de la oferta monetaria e instrumentos crediticios por parte de una autoridad con plenas atribuciones se irá ampliando al manejo de variables no cuantitativas, como los tipos de interés y de descuento, unido al abandono del objetivo de estabilidad cambiaria o del valor externo de la moneda; primero subordinándolo al compromiso de su estabilidad interna, en caso de entrar en conflicto con este, y luego minusvalorándolo o desechándolo. Algo de lo que se desdecirá en Bretton Woods (1944).

Keynes realiza una transformación radical de sus principios y armazón teóricos en la Teoría General (1936), remplazando el problema central de la estabilidad del nivel general de precios por el de la insuficiencia de demanda efectiva, y la baja actividad y desempleo que ésta entraña, generada por una demanda de inversión ligada a factores psicológicos que afectan y determinan la formación de expectativas y el comportamiento de la eficiencia marginal del capital, además de otras decisiones como el consumo y las preferencias de liquidez. Consecuentemente, Keynes ajusta también sus propuestas de actuación para salvar el sistema económico y resolver las fluctuaciones, que ahora centra únicamente en crisis y depresión, desempleo y deflación, aunque no plantea un cambio drástico o revolución.
Así, en la TG desecha que la autoridad pueda, mediante manipulaciones monetarias, controlar o manejar a su antojo los tipos de interés y afirma categóricamente que la política monetaria no es eficaz para paliar o resolver los problemas de desempleo, baja actividad y falta de inversión, ciñendo toda efectividad de la actuación de los mandatarios al control y administración de la inversión y al gasto público como soluciones para la crisis o depresión.

$\mathrm{Y}$ es que Keynes plantea en la TG un sistema económico, unas leyes o métodos de actuación y respuesta por parte de los mercados y la iniciativa privada que, dejados a su libre albedrío, conducen inexorablemente a la depresión y desempleo de los recursos productivos; ya no tanto a procesos cíclicos o de fluctuación. No es tanto que la TG exponga unos fallos de los mercados que la autoridad puede corregir y así encauzar el sistema de mercado, cuanto que la intervención debe ser permanente y firme ${ }^{55}$. Porque, de igual modo que realiza un tratamiento asimétrico entre la inflación, algo deseable, necesario y difícil de lograr, y la deflación, un desastre para la economía, la TG propone una asimetría de funcionamiento en los procesos de ajuste y reajuste propios del sistema económico, según tengan lugar en los auges, donde encuentran y producen respuestas por parte de los agentes que derivarán en frenos y descensos, frente a los que se forman en las crisis o depresiones, donde las expectativas y su forma de generación o formulación impiden la articulación de mecanismos contrarios similares, haciendo persistir los problemas e impidiendo sacar a la economía de su parálisis. Y si llegasen a producirse las respuestas que el modelo clásico plantea, para entonces -considera Keynessería demasiado tarde, pues la situación habría llegado a ser suficientemente mala o dañina como para ser irreversible y su única salida o solución acontecería mediante conflicto o revolución ${ }^{56}$.

Keynes, que en absoluto desea que el sistema económico sufra una transformación revolucionaria y que defiende el sistema de libertad individual, dentro de su concepción aristocrática o elitista, plantea en la TG una salida a través de los dirigentes y Administraciones ${ }^{57}$. Pero piensa no tanto en los políticos como en un cuerpo de funcionarios o burócratas de alto nivel y especialización, en quienes confía.

la TG la expectativa de bajada del interés no incrementa, como suele suponerse o argüirse en los modelos macroeconómicos, la demanda de inversión, sino que la deprime.

55 No se olvide que, aunque los mecanismos propios del sistema de mercado lo conducen a una situación de abatimiento y tendencia al subempleo, permiten también, a su vez, la obtención o existencia de un equilibrio en medio de tal situación de depresión e infrautilización de los recursos productivos. No son meramente fallos del mercado que lo desequilibran y deben encauzarse. Esa era, más bien, su postura previa a la TG, mientras mantuvo un esquema teórico cuantitativista intervencionista.

56 Véase Méndez Ibisate 2012, 98-101. Aunque el argumento es distinto, podría encajar aquí su sentencia: "A largo plazo estamos todos muertos" (Keynes 1923, 80; versión española 1992, 95).

57 Tanto para el párrafo anterior como para este, véanse los capítulos 22 y 24 de la Teoría general. En el capítulo 24 , Keynes expone con claridad que ni aboga por un sistema de socialismo de estado ni propone la propiedad estatal de los medios de producción (Keynes 1973, 378); al contrario, “el individualismo es la mejor salvaguarda de la libertad personal si puede ser purgado de sus defectos y abusos, en el sentido de que, comparado con cualquier otro sistema, amplía considerablemente el campo en el que puede manifestarse la facultad personal.” (Keynes 1973, 380).

Para apreciar su elitismo y arrogancia, en su artículo “¿Soy un liberal?” (1925), afirma: “¿Debo, entonces, afiliarme al Partido Laborista?... Para empezar, es un partido de clase, y su clase no es la mía. Si he de defender intereses enteramente parciales, defenderé los míos. Cuando tenga lugar la lucha de clases como tal, mis patriotismos local y personal, como los de todos los demás, salvo algunos fanáticos desagradables, estarán con mis afines. Puedo estar influido por lo que considero es justicia y buen sentido, pero la guerra de clases me encontrará del lado de la burguesía 
Los elementos o razones para explicar tales cambios y rupturas en Keynes son diversos. Tanto sus ideas, provenientes de su formación y relaciones incluidos Apóstoles y grupo de Bloomsbury-, como los acontecimientos históricos vividos contribuyen a generar en Keynes cierta decepción con el sistema económico y político, que estalla en 1925, tras el retorno al patrón oro de Churchill y su viaje a la Rusia comunista, y que consolidará a partir de 1932, como mucho 1933, tras las críticas académicas formuladas a su Treatise, resultando en un giro analítico radical y su propuesta de un modelo teórico general alternativo para entender la economía ${ }^{58}$.

Según avanza el tiempo, y guiado por una mezcla de estética y diversión intelectual, bases de su moral particular, en Keynes habita la convicción de que el mundo que conoce y hereda, el sistema capitalista o de libre mercado, no es correcto, se desmorona y no funciona adecuadamente, en el sentido de lograr y asegurar una mayor prosperidad continuada. A ello contribuyen, sin duda, unos acontecimientos que, especialmente desde sus cargos en la Administración, le obligan a presenciar, vivir y enfrentarse con crisis y depresiones económicas -incluida la Gran Depresión y sus secuelas - y políticas - incluidas dos guerras mundiales - que, para colmo, rematan la pérdida de la hegemonía británica en el orden político, social, económico y financiero, cuyo desgaste asomaba desde finales del siglo XIX. Keynes interioriza tales acontecimientos como un ultraje, en parte activado por Estados Unidos.

Contrariando sus principios y a sus amistades de Bloomsbury, Keynes procura contribuir desde dentro del sistema a la resolución de buena parte de esos problemas planteados, aunque su temprano desencanto con diferentes líderes políticos, algunos de los cuales apoyó abiertamente en determinadas fases de su vida, hará que, salvo contadas excepciones, los considere -como a los agentes privados en la TGinteresados, volubles, ignorantes e incapaces para realizar los cálculos precisos o detectar los auténticos problemas y tomar las medidas adecuadas para el país; dirigiendo su confianza hacia el conocimiento, racionalidad y mayor información, frente al resto de gente vulgar, de ciertos burócratas y funcionarios de nivel que se encuentran por encima de intereses particulares o espurios de partido y a quienes Key- nes juzga privilegiados, selectos, refinados y distinguidos, además de magnánimos o capaces de vigilar exclusivamente por el bien público, en la toma de decisiones adecuadas ${ }^{59}$.

Ello afecta a políticos como Churchill, que toma la desafortunada decisión de retornar al patrón oro y hacerlo a la paridad de preguerra, ahondando la crisis y el desempleo, pero también al Banco de Inglaterra y sus directores de los que critica su ancestral cultura o comportamiento conservador, rígido y tradicional, casi siempre en exceso, que los disuade de asumir su tarea o cometido y hacerlo con diligencia y profusión: la dirección, manejo e intervención, sin complejos, falta ni descuido, de la política monetaria adecuada a cada situación, que permita amortiguar o solventar las crisis o depresiones, así como los auges que las preceden. Por tanto, la frustración que gradualmente se va determinando en Keynes es doble. No sólo el sistema económico de mercado parecía mostrar disfunciones y anomalías consustanciales o parálisis en los mecanismos de reajuste, reequilibrio o estabilización que, se suponía, incluía, sino que algunas autoridades relevantes y directamente implicadas en su solución o aplicación de recursos y respuestas andaban en exceso torpes en sus decisiones y ejecución.

El surgimiento en los años veinte de un paro masivo que, además, persistía en los primeros años treinta, consolidó en Keynes ese doble descrédito para con el sistema de libre mercado, y las reacciones de sus agentes, y con los políticos o autoridades; no así hacia ciertos funcionarios o burócratas, de los que formaba parte. Su preocupación manifiesta por el desempleo se refleja en sentencias como esta de 1929:

La creencia conservadora de que existe alguna ley de la naturaleza que impide que los hombres se empleen, que es "temerario" contratar hombres y que es financieramente "sano" mantener una décima parte de la población ociosa durante un período indefinido, es disparatadamente improbable; es el tipo de cosa que nadie podría creer si no le hubieran llenado la cabeza con tantas tonterías durante años y años. ${ }^{60}$

Keynes, como muchos economistas ortodoxos, llevaba tiempo proponiendo reformas en el sistema para paliar algunos de sus principales males. Pero aquél parecía resistirse y, además, éstos empeoraban.

educada.” (Keynes 1972, 297). Y en su "Breve perspectiva de Rusia” (1925) dice: “¿Cómo puedo adoptar un credo que, prefiriendo el barro al pescado, exalta al proletariado zafio por encima del burgués y la intelligentsia que, cuales sean sus defectos, representan la calidad de vida y sin duda portan las semillas de todo progreso humano?" (Keynes 1972, 258).

58 A ello cabe añadir su beneplácito, en estos años, hacia las ideas que Knapp formula en su libro de 1905, The State Theory of Money, y en cuya traducción al inglés en 1924, encargada por la Royal Economic Society, colabora Keynes. Véase Ehnts 2019, 1-3. Es en el Treatise on Money (1930) donde Keynes refleja las ideas de Knapp sobre el dinero, para luego relegarlas en su TG (Ehnts 2019, 19). De modo que, en este período, Keynes reclama atención y propugna la idea de que el dinero deriva su valor y aceptación del sello real; es decir, de su carácter de medio legal de pago, otorgado por el Estado, como habían sostenido muchos mercantilistas. El dinero vale y se acepta como tal, porque la autoridad lo dice y le confiere sus características propias: "la era del cartalismo [chartalismo] o del dinero del Estado se alcanzó cuando el Estado reclamó el derecho a declarar qué cosa debería responder como dinero para el dinero por cuenta corriente; cuando reclamó el derecho no sólo de hacer cumplir el diccionario sino también de redactarlo. Más allá de posibles disputas, hoy día todo el dinero civilizado es cartalista.” (Keynes 1971c, 4). Según Ehnts (2019, 21), esto condujo a Keynes a decantarse por una expansión fiscal en tiempos de crisis.

59 Véase, por ejemplo, Ebeling 2004, 18. Las teorías del Public Choice y de la toma de decisiones sociales deberían haber echado por tierra tales argumentos: ni burócratas ni funcionarios llevan un Keynes dentro.

60 Keynes 1972, 90-91. Versión española, Keynes 1988, 101. 
Su decepción con lo que denominaba las hipótesis del laissez faire era tal que le impulsaba a abandonar toda confianza o esperanza en los ajustes del libre mercado, incluso con la mediación e intervención de las autoridades; un modelo que aún defendía en 1923, pero que para 1925 empezaba a derrumbarse. Keynes habla de una economía, de una sociedad, "que está abandonando rápidamente estas hipótesis" de laissez faire y libre competencia ${ }^{61}$.

1925 no sólo es el año de su matrimonio con Lydia Lopokova y del retorno al patrón oro contra el que tanto había luchado Keynes. Es también el año de su viaje a la nueva Rusia, para entonces ya Unión Soviética. Y esta conjunción de hechos tuvo importancia en su proceso de frustración progresiva con el sistema económico y el político, que debía ayudar al primero.

En gran parte no dejaba de considerar como posibles remedios o reformas las propuestas socialistas, que inicialmente entendía como una nueva vía para acabar con los males del desempleo y las crisis. Pero en este viaje, y aunque contempla con cierta admiración algunos de sus logros al respecto, tras comprobar in situ algunos resultados que, dado su carácter aristocrático e independiente, rechazó sin paliativos, añade a sus decepciones previas su desencanto con un sistema que propugna salidas dirigidas y dirigistas de la economía y que abandona el librecambio para proponer un nacionalismo proteccionista.

Aunque Skidelsky afirma, refiriéndose al manejo del dinero y los bancos centrales, que esa doble desconfianza en el sistema de mercado y las autoridades manifiesta la convicción de Keynes en que ciertas funciones públicas quedan mejor desempeñadas por instituciones u organismos más autónomos o independientes del gobierno y no deben estar directamente controladas por el Estado, mi interpretación es que, más bien, muestra, y es fruto de, su percepción elitista, aristocrática e ilustrada del mundo, no necesariamente vinculada a la sangre o condición de cuna, aunque estas contribuyesen. Es el mismo motivo por el que rechazó una solución plenamente dirigista o comunista, frente a los nuevos tiempos y cambios que, también en el sistema económico, estaban teniendo lugar. Y es la razón por la que Keynes abandona el sistema teórico monetarista y busca un nuevo modelo analítico general, tergiversado, que incluso él mismo elude en sus ulteriores contribuciones al sistema monetario y financiero internacional, en los años cuarenta. No es una razón ni una alternativa liberal, aunque, en el sentido que Keynes otorgaba al término, para él sí lo era.

\section{Bibliografía}

Barro, Robert J. 2007. Milton Friedman: Perspectives, Particularly on Monetary Policy. Cato Journal, 27(2), 127-134.

Becker, Gary S. y William J. Baumol. 1952. The Classical Monetary Theory: the Outcome of the Discussion. Economica, XIX(76) (November), 355-376. Existe traducción española "La teoría monetaria clásica: resultado de una discusión", en Joseph J. Spengler y William R. Allen, El pensamiento económico de Aristóteles a Marshall. Madrid: Tecnos, 1971, pp. 767-785.

Cantillon, Richard. [1755] 1931. Essai sur la Nature du Commerce en Général. Edición de Henry Higgs con traducción paralela al inglés, London: MacMillan and Co. for the Royal Economic Society. Existe traducción española Ensayo sobre la naturaleza del comercio en general. México: Fondo de Cultura Económica, 1978.

Coase, Ronald. 1960. The Problem of Social Cost. Journal of Law and Economics, 3 (October), 1-44. URL: http://www. jstor.org/stable/724810.

Ebeling, Richard M. 2004. Henry Hazlitt and the Failure of Keynesian Economics. The Freeman. Ideas on Liberty, 54(9) (November), 15-19.

Ehnts, Dirk H. 2019. Knapp's 'State Theory of Money' and its reception in German academic discourse. Working Paper, Institute for International Political Economy Berlin, Berlin School of Economics and Law, WP No. 115/2019, 27 páginas.

https://EconPapers.repec.org/RePEc:zbw:ipewps:1152019

https://www.econstor.eu/bitstream/10419/193141/1/1049602048.pdf

Friedman, Milton. 1956. The Quantity Theory of Money: A Restatement. En Milton Friedman, Studies in the Quantity Theory of Money. Chicago (Illinois): The University of Chicago Press, 3-21. Reproducido también en Friedman (1969), 51-67.

Friedman, Milton. 1960. A Program for Monetary Stability. New York: Fordham University Press. Existe traducción española de Enrique Mas Montañés, Un programa de estabilidad monetaria y reforma bancaria. Bilbao: Ediciones Deusto, 1970.

Friedman, Milton. 1963. Inflation: Causes and Consequences, Bombay y Londres: Asia Publishing House. Reproducido como capítulo 1 en Friedman (1968b).

Friedman, Milton. 1968a. The Role of Monetary Policy. American Economic Review, 58(1) (March), 1-17. Reproducido en Friedman (1969), 95-110.

${ }_{61}$ Keynes 1972, 224. Esta es la etapa en que Keynes manifiesta mayormente sus posiciones ideológicas y hasta políticas, con ensayos como "Am I a Liberal?" (1925); “A Short View of Russia” (1925); “The End of Laissez-Faire” (1926); e incluso “Can Lloyd George Do It?” (1929), donde plantea elementos que desarrollará en la TG, como el multiplicador. 
Friedman, Milton. 1968b. Dollars and Deficits. Englewood Cliffs (NJ): Prentice-Hall.

Friedman, Milton. 1969. The Optimum Quantity of Money and Other Essays. Chicago: Aldine Publishing Company.

Gómez Betancourt, Rebeca. 2008. Teoría del ciclo económico de F. A. von Hayek: causas monetarias, efectos reales. Cuadernos de Economía, XXVII(48), 47-69.

Hayek, Friedrich A. [1929] 1936. La teoría monetaria y el ciclo económico. Madrid: Editorial Espasa-Calpe.

Hayek, Friedrich A. [1931] 1996. Precios y producción. Madrid: Unión Editorial.

Hume, David. [1752] 1955. Ensayos Políticos. Traducción de Enrique Tierno Galván. Madrid: Instituto de Estudios Políticos, Colección Civitas.

Humphrey, Thomas M. 1990. Fisherian and Wicksellian Price-Stabilization Models in the History of Economic Thought. Economic Review. The Federal Reserve Bank of Richmond, 76(3) (May-June), 3-12.

Humphrey, Thomas M. 1991. Nonneutrality of Money in Classical Monetary Thought. Economic Review. The Federal Reserve Bank of Richmond, 77(2) (March-April), 3-15.

Keynes, John Maynard. 1923. A Tract on Monetary Reform. London: Macmillan and Co. Existe traducción española de Carlos Rodríguez Braun, Breve tratado sobre la reforma monetaria. México: F. C. E., 1992.

Keynes, John Maynard. [1930b] 1934. A Treatise on Money. The Applied Theory of Money. Vol. 2. London: MacMillan and Co.

Keynes, John Maynard. 1937. The General Theory of Employment. The Quarterly Journal of Economics, 51(2) (February), 209-223. Versión electrónica de Oxford University Press. URL: http://www.jstor.org/stable/1882087

Keynes, John Maynard. [1913] 1971a. Indian Currency and Finance. The Collected Writtings of John Maynard Keynes. Vol. I. London: Macmillan \& St. Martin's Press for the Royal Economic Society.

Keynes, John Maynard. [1919] 1971b. The Economic Consequences of the Peace. The Collected Writtings of John Maynard Keynes. Vol. II. London: Macmillan \& St. Martin's Press for the Royal Economic Society.

Keynes, John Maynard. [1930a] 1971c. A Treatise on Money. The Pure Theory of Money. Vol. 1. The Collected Writings of John Maynard Keynes. Vol. V. London: Macmillan and St. Martin's Press for the Royal Economic Society. Existe traducción española Tratado sobre el dinero. Madrid: Fundación ICO y Síntesis, 2010.

Keynes, John Maynard. [1931] 1972. Essays in Persuasion. The Collected Writings of John Maynard Keynes. Vol. IX. London: Macmillan and St. Martin's Press for the Royal Economic Society. Existe traducción española de Jordi Pascual, Ensayos de Persuasión, Barcelona: Crítica, 1988.

Keynes, John Maynard. [1936] 1973. The General Theory of Employment, Interest and Money. The Collected Writings of John Maynard Keynes. Vol. VII. London: Macmillan and Cambridge University Press for The Royal Economic Society.

Keynes, John Maynard. [1936] 1981. Teoría general de la ocupación, el interés y el dinero. $2^{\mathrm{a}}$ edición corregida (1965), $12^{\mathrm{a}}$ reimpresión. México: F.C.E. Texto revisado y corregido con Rodríguez Braun (1986).

Keynes, John Maynard. [1929] 1988. ¿Puede hacerlo Lloyd George? Ensayos de Persuasión. Barcelona: Crítica, pp. 96133.

Keynes, John Maynard. [1930c] 2008. The Great Slump of 1930. Dos artículos originalmente publicados en The Nation and Athenceum, el 20 y 27 de diciembre de 1930. Versión electrónica de A Project Gutenberg Canada Ebook: http:// www.gutenberg.ca/ebooks/keynes-slump/keynes-slump-00-h.html.

Versión española: La gran depresión de 1930. Ensayos de Persuasión. Barcelona: Crítica, 1988, pp. 134-142.

Laidler, David. [1969] 1980. La demanda de dinero. Teorías y evidencia empírica. Barcelona: Antoni Bosch. $2^{\mathrm{a}}$ ed. revisada.

Laidler, David. 1999. Fabricating the Keynesian Revolution. Studies of the Inter-war Literature on Money, the Cycle and Unemployment. Cambridge: Cambridge University Press.

Laidler, David. 2018. Why the Fuss? - Friedman (1968) After Fifty Years. Department of Economics Research Reports, 2018-4. London (Ontario): Department of Economics, University of Western Ontario. 12 páginas.

http://economics.uwo.ca/research/research_papers/department_working_papers.html

Lucas, Robert E. Jr. 1996. Monetary Neutrality. Journal of Political Economy, 104(4) (August), 661-682.

Mantoux, Étienne. 1946. The Carthaginian Peace or The Economic Consequences of Mr. Keynes. London: Geoffrey Cumberlege, Oxford University Press.

Marshall, Alfred. [1887] 1965a. Remedies for Fluctuations of General Prices. En Pigou (ed.) (1965), pp. 188-211.

Marshall, Alfred. [1923] 1965b. Money, Credit and Commerce. New York: Augustus M. Kelley.

Marshall, Alfred. [1926] 1979. Official Papers by Alfred Marshall. Westport (Connecticut): Greenwood Press.

Méndez Ibisate, Fernando. 1988a. Marshall y la Ley de Say. La teoría monetaria en Alfred Marshall, Tesis doctoral, Madrid, Universidad Complutense de Madrid, Apéndice H, pp. 1132-1154.

Méndez Ibisate, Fernando. 1988b. Teorías decimonónicas del dinero en el siglo XX. Información Comercial Española, 656 (abril), 79-92.

Méndez Ibisate, Fernando. 1990. Cantillon y la independencia de los bancos centrales. España Económica, 3.715 (febrero), 38 .

Méndez Ibisate, Fernando. 1993a. Aspectos macroeconómicos del pensamiento de Alfred Marshall: teoría monetaria. Revista de Historia Económica, XI(2), 337-364. 
Méndez Ibisate, Fernando. 1993b. El 'Ensayo sobre el dinero' y 'Una nota matemática acerca del valor del dinero’ de Alfred Marshall: un estudio preliminar. Libertas, X(19), 33-64.

Méndez Ibisate, Fernando. 1996. Alfred Marshall y el banco central: política monetaria. Revista de Historia Económica, XIV(3), 641-669.

Méndez Ibisate, Fernando. 2000. Estudio Preliminar. En Thornton (2000), pp. 9-61.

Méndez Ibisate, Fernando. 2003. Mecanismos de control y reglas de política monetaria: una experiencia histórica reciente. En Estudios de Historia y de Pensamiento Económico. Homenaje al profesor Francisco Bustelo García del Real. Madrid: Editorial Complutense, pp. 541-566.

Méndez Ibisate, Fernando. 2004a. Marginalistas y neoclásicos. Madrid: Síntesis.

Méndez Ibisate, Fernando. 2004b. Cantillon effect. En Julio Segura y Carlos Rodríguez Braun (eds.), An Eponymous Dictionary of Economics, Cheltenham (UK) \& Northampton (MA, USA): Edward Elgar, pp. 37-38.

Méndez Ibisate, Fernando. 2006. Setenta años de la Teoría General de Keynes. Una revisión crítica. Documento de Trabajo, núm. 2006-04, Facultad de Ciencias Económicas y Empresariales, Universidad Complutense de Madrid. Versión electrónica, http://eprints.ucm.es/6853/1/0604.pdf. Última visita 28 de febrero de 2019.

Méndez Ibisate, Fernando. 2012. La "Teoría General” de Keynes. Una lectura crítica tras setenta y cinco años y otra gran crisis. Norderstedt y Saarbrücken (Alemania): Editorial Académica Española.

Méndez Ibisate, Fernando. 2013. Antecedentes de la Gran Recesión: responsabilidades de la política monetaria. Actas del I Congreso de Economía y Libertad: «La Gran Recesión y sus salidas», organizado por la Universidad Católica de Ávila y el Instituto Juan de Mariana, del 22 al 24 de noviembre de 2012. Ávila: Universidad Católica de Ávila, pp. 99-121. ISBN: 978-84-15300-08-3.

Méndez Ibisate, Fernando. 2014a. John Maynard Keynes. Período cuantitativista y reformador monetario. En David Sanz Bas (coord.), Historia del Pensamiento Económico. Capítulo 9. Ávila: Universidad Católica de Ávila, pp. 291-348. ISBN: 978-84-9040-269-6.

Méndez Ibisate, Fernando. 2014b. John Maynard Keynes. El giro de la Teoría general del empleo, el interés y el dinero. En David Sanz Bas (coord.), Historia del Pensamiento Económico. Capítulo 10. Ávila: Universidad Católica de Ávila, pp. 349-430. ISBN: 978-84-9040-269-6.

Méndez Ibisate, Fernando. 2015. Un análisis del pensamiento económico contemporáneo a través de un keynesiano ecléctico: Edmund S. Phelps. En José Luis García Ruiz y José María Ortiz-Villajos (eds.), Ensayos de Historia y Pensamiento Económicos. Homenaje al Prof. Juan Hernández Andreu, Madrid: Delta Publicaciones, pp. $205-231$.

Méndez Ibisate, Fernando. 2018. Un soplo de Marx y un aire de socialismo en Marshall. Iberian Journal of the History of Economic Thought, 5(2), 113-132.

Mill, John Stuart. [1848] (1965). Principles of Political Economy with Some of Their Applications to Social Philosophy. En J. M. Robson (ed.), Collected Works of John Stuart Mill, Vols. II y III, Toronto: University of Toronto Press and London: Routledge \& Kegan Paul. Existe traducción española Principios de Economía Política con algunas de sus aplicaciones a la filosofía social. México: Fondo de Cultura Económica, 1978.

Phelps, Edmund S. 1967. Phillips Curves, Expectations of Inflation and Optimal Unemployment over Time. Economica, 34(135), 254-281.

Pigou, Arthur Cecil. (ed.). 1965. Memorials of Alfred Marshall. New York: Augustus M. Kelley.

Rodríguez Braun, Carlos. 1986. Debilidades en la edición del Fondo de Cultura Económica de la «Teoría General» de Keynes. Investigaciones Económicas (Segunda Época), X(2), 411-417.

Rodríguez Braun, Carlos. 2006. Grandes Economistas. Madrid: Pirámide. $1^{\mathrm{a}}$ edición 1997.

Rojo, Luis Ángel. 1984. Keynes, su tiempo y el nuestro. Madrid: Alianza.

Rothbard, Murray N. 1992. Keynes, the Man. En Mark Skousen (ed.), Dissent on Keynes. A Critical Appraisal of Keynesian Economics. New York: Preager Publishers, pp. 171-198. Reproducido en la web del Ludwig von Mises Institute, http://mises.org/books/dissent.pdf; también en: http://mises.org/daily/3845

Skidelsky, Robert. 1983. John Maynard Keynes Vol. 1: Hopes Betrayed. 1883-1920. London: Macmillan. Existe traducción española John Maynard Keynes. Esperanzas frustradas: 1883-1920. Madrid: Alianza Ed., 1986.

Skidelsky, Robert. 1992. John Maynard Keynes Vol. 2: The Economist as Saviour. 1920-1937. London: Macmillan.

Skidelsky, Robert. 1998. Keynes. Madrid: Alianza.

Skidelsky, Robert. 2000. John Maynard Keynes Vol. 3: Fighting for Freedom. 1937-1943. New York: Viking.

Skidelsky, Robert. 2013. John Maynard Keynes. La biografía definitiva del economista más influyente de nuestro tiempo. Barcelona: RBA.

Thornton, Henry. [1811] (1962). Two Speeches of Henry Thornton, Esq. on the Bullion Report, May 1811. En Henry Thornton [1802] (1962). An Essay into the Nature and Effects of the Paper Credit of Great Britain. Edición de F. A. v. Hayek. London: Frank Cass \& Co. Ltd. Reimpresión de la edición de 1939. Apéndice III, pp. 323-361.

Thornton, Henry. [1802] (2000). Una investigación sobre la naturaleza y los efectos del crédito papel de Gran Bretaña. Madrid: Pirámide.

Wicksell, Knut. [1898] (1965). Interest and Prices. A Study of the Causes Regulating the Value of Money. Traducción al inglés de R. F. Kahn con introducción de Bertil Ohlin. New York: Augustus M. Kelley. 